\title{
UPFront and center in RNA decay: UPF1 in nonsense- mediated mRNA decay and beyond
}

\author{
YOON KI KIM ${ }^{1,2}$ and LYNNE E. MAQUAT ${ }^{3,4}$ \\ ${ }^{1}$ Creative Research Initiatives Center for Molecular Biology of Translation, Korea University, Seoul 02841, Republic of Korea \\ ${ }^{2}$ Division of Life Sciences, Korea University, Seoul 02841, Republic of Korea \\ ${ }^{3}$ Department of Biochemistry and Biophysics, School of Medicine and Dentistry, University of Rochester, Rochester, New York 14642, USA \\ ${ }^{4}$ Center for RNA Biology, University of Rochester, Rochester, New York 14642, USA
}

\begin{abstract}
Nonsense-mediated mRNA decay (NMD), which is arguably the best-characterized translation-dependent regulatory pathway in mammals, selectively degrades mRNAs as a means of post-transcriptional gene control. Control can be for the purpose of ensuring the quality of gene expression. Alternatively, control can facilitate the adaptation of cells to changes in their environment. The key to NMD, no matter what its purpose, is the ATP-dependent RNA helicase upstream frameshift 1 (UPF1), without which NMD fails to occur. However, UPF1 does much more than regulate NMD. As examples, UPF1 is engaged in functionally diverse mRNA decay pathways mediated by a variety of RNA-binding proteins that include staufen, stem-loop-binding protein, glucocorticoid receptor, and regnase 1. Moreover, UPF1 promotes tudor-staphylococcal/ micrococcal-like nuclease-mediated microRNA decay. In this review, we first focus on how the NMD machinery recognizes an NMD target and triggers mRNA degradation. Next, we compare and contrast the mechanisms by which UPF1 functions in the decay of other mRNAs and also in microRNA decay. UPF1, as a protein polymath, engenders cells with the ability to shape their transcriptome in response to diverse biological and physiological needs.
\end{abstract}

Keywords: nonsense-mediated mRNA decay; Staufen-mediated mRNA decay; UPF1

\section{INTRODUCTION}

The ATP-dependent RNA helicase upstream frameshift 1 (UPF1) is required for the nonsense-mediated mRNA decay (NMD) of all eukaryotic NMD targets studied to date (Brogna et al. 2016; Hug et al. 2016; Karousis et al. 2016; Saveanu and Jacquier 2016; Celik et al. 2017; Karousis and Mühlemann 2018; Raimondeau et al. 2018). It has been known for almost $20 \mathrm{yr}$ that the abundance of UPF1 in human HeLa cells is $\sim 10$-fold higher than the abundance of the two other UPF proteins-UPF2 and UPF3X (also called UPF3B) - that function in NMD (Maquat and Serin 2001), offering an early indication that UPF1 functions may extend beyond NMD. Since that realization, ample evidence has made it clear that UPF1 multitasks by contributing to other RNA decay pathways. Additionally, the finding that UPF1 can function as an E3-ubiquitin ligase that represses myogenesis provides an example of how UPF1 function in NMD can be coordinated with its function in

\footnotetext{
Corresponding authors: yk-kim@korea.ac.kr, lynne_maquat@ urmc.rochester.edu

Article is online at http://www.rnajournal.org/cgi/doi/10.1261/rna. 070136.118. Freely available online through the RNA Open Access option.
}

protein decay (Takahashi et al. 2008; Feng et al. 2017)_a link that will undoubtedly be extended in the future to other cellular processes.

To date, UPF1-dependent RNA decay pathways include NMD, staufen (STAU)-mediated mRNA decay (SMD), replication-dependent histone mRNA decay (HMD), glucocorticoid receptor-mediated mRNA decay (GMD), regnase 1-mediated mRNA decay (RMD), and tudorstaphylococcal/micrococcal-like nuclease (TSN)-mediated microRNA decay (TumiD). Future studies will undoubtedly discover additional pathways. Given that UPF1 binds to all physically accessible transcripts in cells (Hogg and Goff 2010; Hurt et al. 2013; Zünd et al. 2013; Kurosaki et al. 2014), the participation of UPF1 in specific RNA decay pathways means that UPF1 must be purposefully recruited to and thereby activated on each type of substrate. In this review, we outline how substrates of each UPF1-dependent RNA decay pathway recruit and utilize UPF1 for their very distinct purposes. 


\section{NMD: DUAL ROLES OF UPF1 IN CONTROLLING THE QUALITY OR QUANTITY OF GENE EXPRESSION}

It is important that eukaryotic genes be expressed at the right time and place, and at an appropriate level. However, gene expression is not without errors: Abnormally synthesized gene products routinely arise as a consequence of mistakes made during gene replication, gene transcription, pre-mRNA processing, and/or mRNA translation. These mistakes can result in the production of improperly functional or nonfunctional proteins that could be deleterious to cellular metabolism. Thus, aberrant gene products would ideally be detected and eliminated by cells as a means to increase the fidelity of gene expression, thereby ensuring homeostasis. To this end, eukaryotic cells have evolved highly sophisticated mechanisms of quality control.

An estimated $5 \%-30 \%$ of human transcripts are faulty because they harbor a premature termination codon (PTC; Bhuvanagiri et al. 2010; Huang and Wilkinson 2012; Nguyen et al. 2014), some of which may yield truncated polypeptides. Fortunately, all eukaryotic cells that have been examined have developed nonsense-mediated mRNA decay (NMD) for quality control. NMD recognizes and eliminates PTC-containing mRNAs as a means to reduce the production of aberrant and potentially toxic proteins. NMD also eliminates the PTC-containing mRNAs that typify an estimated $30 \%$ of genetic or acquired diseases in humans. For these affected individuals, disease is due to the absence of full-length functional protein and, if genetic, is recessively inherited. However, many people with dominantly inherited diseases harbor a PTC that fails to trigger NMD. In this case, disease is due to the production of a truncated protein that is detrimental to cell function even when the other allele is normal and expressed (Bhuvanagiri et al. 2010; Huang and Wilkinson 2012; Nguyen et al. 2014).

In addition to its quality-control role, NMD also regulates the stability of $\sim 5 \%-10 \%$ of normal, physiologic mRNAs. This is exemplified by the many developmental and environmental changes that reduce the efficiency of NMD so that natural NMD targets are expressed. Among these NMD targets are groups of mRNAs producing proteins that promote the appropriate cellular response (Kurosaki et al. 2019). In many cases, the efficiency of NMD is reduced in response to environmental change by a mechanism that inhibits UPF1 function in the pathway. For example, an increased ratio of STAU1 relative to UPF2 results in more SMD and less NMD during myogenesis since each protein competes for binding to UPF1 (Gong et al. 2009). Among the group of NMD targets stabilized are mRNAs whose encoded proteins promote the maturation of myoblasts to multinucleated myotubes (Gong et al. 2009). As another example, microRNAs that target UPF1 mRNA inhibit UPF1 production during neurogenesis so as to promote differentiation from the stem-cell state to the neural state (Bruno et al. 2011; Lou et al. 2014). As a final example, severe DNA damage by chemotherapeutics decreases the efficiency of NMD because UPF1 is cleaved by caspases, thereby promoting apoptosis (Jia et al. 2015; Popp and Maquat 2015). The reader is referred to Kurosaki et al. (2019) for additional ways in which changes in the efficiency of NMD by targeting UPF1 function contribute to cellular adaptation. Most notably among them, NMD offers anti-viral mechanisms that viruses often counter by sequestering, inactivating, or down-regulating the abundance of UPF1. In addition, depending on how cancers evolve, UPF1 may be mutated (e.g., see Liu et al. 2014) or up-regulated (El-Bchiri et al. 2008; Bokhari et al. 2018) to promote tumor-cell survival.

\section{NMD: RECOGNITION OF NMD SUBSTRATES}

NMD serves two masters in cells: One promotes the quality of gene expression, and the other promotes adaptation to changing environments by regulating the quantity of gene expression. For each purpose, the NMD pathway consists of two essential steps: substrate recognition, and substrate degradation (Fig. 1). Despite extensive studies of each step, some details remain obscure. We overview a basic model for the two steps from the vantage point of UPF1, considering its essential role in NMD. We subsequently introduce possible variations of this model to accommodate that there are branches of NMD that differ in their requirement for particular NMD factors.

Newly synthesized intron-containing pre-mRNAs, bound at their $5^{\prime}$-caps by the nuclear cap-binding complex (CBC) that consists of a heterodimer of cap-binding protein (CBP) 80 and CBP20 (Maquat et al. 2010; Gonatopoulos-Pournatzis and Cowling 2014; Müller-McNicoll and Neugebauer 2014), generally undergo cotranscriptional splicing (Nojima et al. 2018). Splicing removes introns and connects exons to generate mRNAs, with the possibility of producing one or more differentially spliced mRNA isoforms depending on cell type or developmental stage (Singh et al. 2015). As a consequence of splicing, a protein complex called the exon-junction complex (EJC) is deposited onto newly synthesized mRNAs $\sim 20-24$ nt upstream of the resulting exon-exon junctions with an estimated efficiency of $80 \%$ (Le Hir et al. 2000, 2016; Bono et al. 2006; Singh et al. 2012; Boehm and Gehring 2016; Woodward et al. 2017). Once matured at their 3'ends by endonucleolytic cleavage and polyadenylation that, like splicing, can produce alternative mRNA isoforms, the resulting mature mRNAs are exported from the nucleus to cytoplasm carrying the CBC, EJCs, and other RNA-binding proteins (Maquat et al. 2010; Gonatopoulos-Pournatzis and Cowling 2014; Müller-McNicoll and Neugebauer 2014). In the cytoplasm, mRNAs continue to undergo dramatic remodeling of their associated proteins, including 


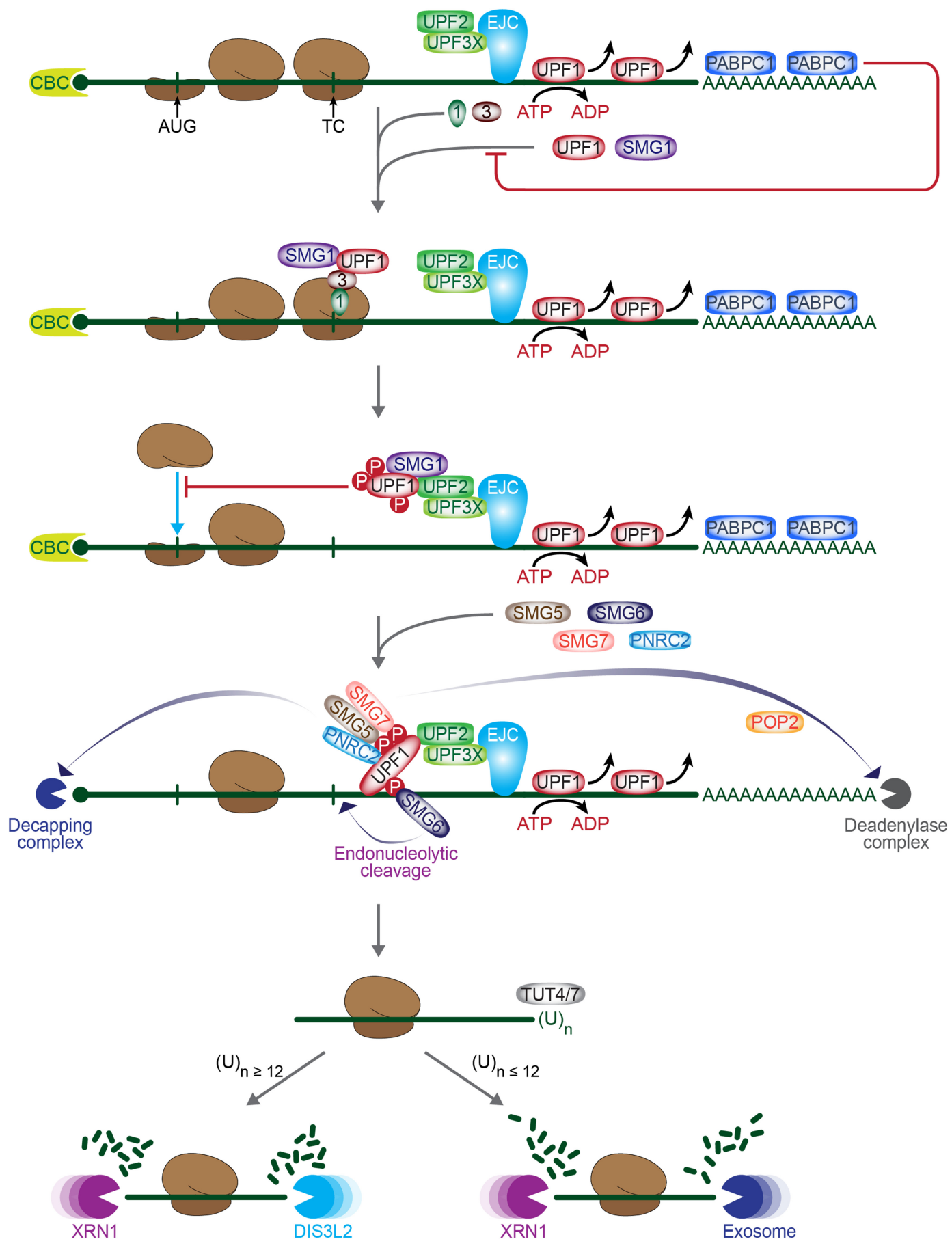

FIGURE 1. Stepwise processes for nonsense-mediated mRNA decay (NMD). Whether a termination codon (TC) does or does not trigger NMD is determined by two opposing events, respectively, termination-delaying (i.e., NMD-stimulating) events, which are promoted by factor(s) such as a 3'UTR EJC or a structured 3'UTR, each of which has a propensity for binding the UPF1 ATP-dependent RNA helicase, or termination-promoting (i.e., NMD-antagonizing) factor(s) such as PABPC1. Shown here are the steps that constitute 3'UTR EJC-dependent NMD. Briefly, when a 3'UTR EJC remains after translation termination at a TC, UPF1, its kinase SMG1 (and additional SMG factors that will not be discussed here) form the SURF complex together with the two termination factors eRF1 and eRF3. Subsequently, UPF1 and SMG1 either bridge or move to the EJC, at which point EJC-bound UPF2 binding to the CH domain of UPF1 induces a large conformational change in UPF1, concomitantly promoting the phosphorylation of UPF1 by the SMG1 kinase and, possibly, also promoting its helicase activity. Phosphorylated UPF1 represses translation by precluding further translation initiation events and also recruits factors that either directly (SMG6) or indirectly (SMG5-SMG7 and/or PNRC2) result in decay. Endoribonucleolytic cleavage occurs near the TC by SMG6, whereas DCP2-DCP1A decapping followed by 5'-to-3' exoribonucleolytic activities are recruited by PNRC2, and CCR4-POP2 deadenylating as well as 3'-to-5' exosome activities are recruited by SMG5-SMG7 Ribosome-bound NMD decay intermediates can be uridylated at their $3^{\prime}$-ends by TUT4 and TUT7 to promote further $3^{\prime}$-to- $5^{\prime}$ exoribonucleolytic by DIS3L2 and/or the exosome. Terminal uridylation can also induce decapping followed by XRN1-mediated 5'-to-3' degradation. 
replacement of the $\mathrm{CBC}$ by the cytoplasmic CBP eukaryotic translation initiation factor (elF) 4E and loss of the EJCs (Sato and Maquat 2009; Maquat et al. 2010). Of particular relevance to $\mathrm{NMD}$, the $\mathrm{CBC}$ not only remains bound to 5 -caps during mRNA export to the cytoplasm (Ishigaki et al. 2001; Lejeune et al. 2002), but it also recruits ribosomes to support the pioneer, or first, round of mRNA translation in the cytoplasm (Ishigaki et al. 2001; Kim et al. 2009; Choe et al. 2012, 2014b).

There are two categories of NMD, and both are tightly linked to the process of protein synthesis, during which termination codons are recognized. NMD that involves an EJC situated downstream from a termination codon, i.e., 3'-untranslated region (3'UTR) EJC-dependent NMD, largely occurs during the translation of newly synthesized, CBC-bound mRNAs undergoing the pioneer round of translation. Depending on the efficiency of translation initiation and the length of the open reading frame, the pioneer round of translation may involve mRNAs that are bound by one or more ribosomes (Chiu et al. 2004; Isken and Maquat 2007; Isken et al. 2008; Kim et al. 2009; Apcher et al. 2011; Sharma et al. 2012). While it is possible that the fraction of 3'UTR EJC-dependent NMD substrates that escapes decay while bound by the CBC may be degraded later, during the subsequent rounds of translation mediated by elF4E (Durand and Lykke-Andersen 2013; Rufener and Mühlemann 2013), the fraction of the total pool of NMD substrates that is degraded while bound by $\mathrm{CBC}$ relative to by elF4E remains unclear. That noted, single-molecule studies showed that decay occurs rapidly once an mRNA is exported to the cytoplasm, possibly before CBC is replaced by elF4E (Trcek et al. 2013).

In addition to 3'UTR EJC-dependent NMD, there is NMD that occurs independent of a $3^{\prime}$ UTR EJC, often as a consequence of translation termination at the normal termination codon rather than at a PTC (Wang et al. 2002; Bühler et al. 2006; Matsuda et al. 2007; Eberle et al. 2008). Cells define whether or not a termination codon (TC) triggers either type of NMD depending on the ability of UPF1 to be recruited and phosphorylated downstream from the TC ( $\mathrm{He}$ and Jacobson 2015; Karousis et al. 2016; Kurosaki et al. 2019).

When an elongating ribosome reaches a TC that does not trigger NMD, as typifies most normal TCs, translation termination is relatively efficient. A ternary complex consisting of eukaryotic release factor (eRF)1, eRF3, and GTP is recruited to the ribosomal A site (Dever and Green 2012; Joazeiro 2017; Hellen 2018; Schuller and Green 2018). Once eRF1 binds the TC, GTP hydrolysis by eRF3 induces a conformational change in eRF1 and consequently activates hydrolysis of the polypeptide from the polypeptidyl-tRNA in the ribosomal $P$ site. These processes are promoted by cytoplasmic poly(A)-binding protein 1 (PABPC1) binding to the amino-terminal region of eRF3
(Hoshino et al. 1999; Uchida et al. 2002; Ivanov et al. 2008) independently of GTP hydrolysis by eRF3 and polypeptide release by eRF1 (Ivanov et al. 2016). In addition, release of the polypeptide, eRF3, and GDP is coupled via eRF1 to recruitment of the ATP-binding cassette subfamily $E$ member 1 (ABCE1; also called RNase $L$ inhibitor $1, \mathrm{RL} / 1)$, which leads to dissociation of the 605 ribosomal subunit from the $40 \mathrm{~S}$ ribosomal subunit and facilitates efficient ribosome recycling (Khoshnevis et al. 2010; Pisarev et al. 2010; Dever and Green 2012).

However, when an elongating ribosome reaches a TC that does trigger NMD, translation termination is relatively inefficient because of factors that delay the process. In the case of 3'UTR EJC-dependent NMD, the EJC delays termination. Delay is in part due to the binding of UPF1 and its phosphatidylinositol 3-kinase-related kinase SMG1 to the terminating ribosome along with the eRF1-eRF3 complex, forming the SURF complex (SMG1-UPF1-eRF1eRF3; Kashima et al. 2006). The binding of UPF1 to eRF3 in SURF appears to out-compete binding of the termination-promoting factor PABPC1 to eRF3 (Singh et al. 2008). Subsequently, the amino-terminal cysteine- and histidine-rich domain of UPF1 interacts with the carboxyterminal region of EJC-bound UPF2 (Weng et al. 1996; Serin et al. 2001; Kadlec et al. 2006; Chamieh et al. 2008), whose third middle domain of elF4G (MIF4G) domain interacts with the amino-terminal ribonucleoprotein-type RNAbinding domain of the EJC component UPF3X (Serin et al. 2001; Kadlec et al. 2004; Chamieh et al. 2008). Here again, interactions between NMD factors at the TC and the EJC reduce the efficiency of termination by antagonizing the termination-promoting contributions of PABPC1 (Eberle et al. 2008; Ivanov et al. 2008; Singh et al. 2008). This leads to the formation of an mRNA decay-inducing complex (DECID), which is promoted by the RNA helicase DHX34 (Hug and Cáceres 2014; Melero et al. 2016), and UPF1 activation by SMG1-mediated phosphorylation (Kashima et al. 2006; Kurosaki and Maquat 2013; Kurosaki et al. 2014; Durand et al. 2016). In the case of 3'UTR EJC-independent NMD, UPF1 is preferentially bound to the $3^{\prime} U T R$ either because of a $3^{\prime}$ UTR structure that impedes $5^{\prime}$-to- $3^{\prime}$ UPF1 helicase activity or because the $3^{\prime}$ UTR is sufficiently long to generate a higher probability of being occupied by promiscuously bound UPF1 (Zünd et al. 2013; Imamachi et al. 2017). Thus, in both 3'UTR EJC-dependent NMD and 3'UTR EJC-independent NMD, termination-delaying (i.e., NMD-stimulating) factor(s) that result from UPF1 recruitment to, respectively, a 3'UTR EJC or the 3'UTR itself, outcompete termination-promoting (i.e., NMD-antagonizing) factor(s) such as PABPC1. The effect of these terminationdelaying factors may be overridden by the binding of a cellular protein, such as polypyrimidine tract binding protein or hnRNP L, immediately downstream from the termination codon (Ge et al. 2016; Kishor et al, 2018). Notably, once UPF1 is phosphorylated, the NMD substrate 
is further remodeled so that additional translation initiation events are precluded and mRNA degradative activities are recruited, both of which are required for mRNA decay (see below).

An alternative mechanism by which a TC could be recognized was recently proposed based on assays of translation termination in vitro using recombinant proteins (Neu-Yilik et al. 2017). Instead of finding a role for UPF1 in translation termination, it was discovered that translation termination was delayed by the direct interaction of UPF3X with eRF3, and that UPF3X directly binds to UPF1 even in the absence of UPF2, consistent with previous data showing that cellular UPF3X and UPF1 coimmunoprecipitate in the absence of UPF2 (Gong et al. 2009). The in vitro experiments used limiting amounts of eRF1 and eRF3 and an excess of UPF3X with the goal of recapitulating the inefficient translation termination that is observed during cellular NMD but simultaneously complicating interpretations. Nevertheless, these experiments might provide molecular clues to the branch of cellular 3'UTR EJC-dependent NMD that relies on UPF1 and UPF3X but not UPF2 (Gehring et al. 2005; Chan et al. 2007).

\section{NMD: SELECTIVE SUBSTRATE DEGRADATION}

Once UPF1 undergoes phosphorylation, it inhibits further translation initiation events on the NMD substrate and recruits mRNA decay activities. Translation inhibition is mediated by phosphorylated UPF1 binding to the two highest molecular weight subunits of elF3 that constitute the $43 \mathrm{~S}$ preinitiation complex poised at the initiating AUG codon: Binding precludes 605 ribosomal subunit joining to the $43 \mathrm{~S}$ preinitiation complex so as to prevent formation of a translationally active $80 \mathrm{~S}$ ribosome (Isken et al. 2008). Without translational repression, NMD fails to occur (Isken et al. 2008). Phosphorylated UPF1 additionally recruits mRNA degradative activities both directly, as exemplified by SMG6, and via other NMD factors, including the heterodimer SMG5-SMG7 and/or the protein-rich nuclear receptor coactivator 2 (PNRC2) (Anders et al. 2003; Chiu et al. 2003; Ohnishi et al. 2003; Unterholzner and Izaurralde 2004; Fukuhara et al. 2005; Cho et al. 2009; Eberle et al. 2009; Okada-Katsuhata et al. 2012). Given the propensity for steady-state hypophosphorylated UPF1 to bind any cellular RNA that is physically accessible (Hogg and Goff 2010; Kurosaki and Maquat 2013; Zünd et al. 2013; Kurosaki et al. 2014), binding by phosphorylated UPF1 provides a reliable molecular identifier of cellular NMD substrates (Kurosaki et al. 2014, 2018; Durand et al. 2016; Imamachi et al. 2017).

Mammalian-cell NMD involves both endoribonucleolytic and exoribonucleolytic activities (Chen and Shyu 2003; Lejeune et al. 2003; Couttet and Grange 2004; Huntzinger et al. 2008; Eberle et al. 2009). The endoribonuclease SMG6 cleaves mRNA close to the TC, resulting in
5 -cleavage fragments and 3 '-cleavage fragments, the latter of which are still polyadenylated (Eberle et al. 2009). These fragments are subsequently degraded by, respectively, the $3^{\prime}$-to- 5 ' multisubunit exosome and the 5'-to-3' exoribonuclease XRN1 (Huntzinger et al. 2008; Eberle et al. 2009). Exoribonucleolytic decay by deadenylation is mediated by SMG5-SMG7: A CCR4-NOT deadenylase complex is recruited via a direct interaction between SMG7 and the POP2 catalytic subunit of the CCR4-NOT deadenylase complex, eliciting deadenylation followed by exosome-mediated 3'-to-5' degradation (Loh et al. 2013). Decapping followed by $5^{\prime}$-to- $3^{\prime}$ degradation is activated by PNRC2 in concert with or independently of the SMG7-POP2 interaction (Cho et al. 2009, 2013a; Loh et al. 2013). PNRC2 binds DCP1A, a component of the decapping complex, to elicit decapping, which is followed by 5'-to-3' exoribonucleolytic cleavage (Cho et al. 2009; Lai et al. 2012; Loh et al. 2013; Mugridge et al. 2016; Nicholson et al. 2018). Since (i) artificially tethered SMG5 causes rapid degradation of reporter mRNAs in a PNRC2dependent and SMG7-dependent manner (Nicholson et al. 2018), and (ii) PNRC2 preferentially associates with SMG5 rather than SMG6 or SMG7 (Cho et al. 2013a), it is likely that SMG5 forms two mutually exclusive complexes: SMG5-SMG7 or SMG5-PNRC2. The resulting alternative pathways may contribute to the observed preference of particular NMD substrates for particular decay-inducing factors downstream from UPF1 phosphorylation (Kurosaki et al. 2018). A structural analysis revealed that PNRC2 bridges the interaction between DCP1A and the DCP2 decapping enzyme, synergistically acting with DCP1A to stimulate DCP2 decapping activity (Lai et al. 2012). This, together with a recent kinetic analysis of PNRC2 revealing that a conserved short linear motif in PNRC2 enhances both substrate binding and the catalytic step of decapping (Mugridge et al. 2016), suggests that PNRC2 functions during NMD as a decapping co-activator and an adaptor that links UPF1 to the decapping complex (Cho et al. 2009; Lai et al. 2012; Nicholson et al. 2018).

Recent transcriptome-wide characterizations of NMD decay intermediates have uncovered additional aspects of the degradative process (Kurosaki et al. 2018). For one, NMD decay intermediates can be uridylated at their 3'ends by the terminal uridylyl transferases, TUT4 and TUT7. This appears to promote subsequent 3 '-to- $5^{\prime}$ exoribonucleolytic decay by either the DIS3-like 3'-to-5' exoribonuclease DIS3L2 or the exosome, depending on the length of terminally added uridine nucleotides. Nontemplated 3 '-end uridines are also known to trigger decapping followed by XRN1-mediated 5'-to-3' degradation by recruiting the LSM1-7 complex (Song and Kiledjian 2007; Rissland and Norbury 2009). Data indicate that oligouridylated NMD decay intermediates are bound not only by phosphorylated UPF1 but also by one or more ribosomes (Kurosaki et al. 2018). Moreover, the 3 '-end addition of a 
nontemplated nucleotide other than uridine inhibits decay (Kurosaki et al. 2018).

\section{NMD: MOLECULAR ACTIVITIES OF UPF1}

Mammalian UPF1, which belongs to the superfamily 1 of RNA helicases, exhibits RNA-dependent ATPase and $3^{\prime}$-to-5' helicase activities, both of which are crucial for NMD (Weng et al. 1996; Franks et al. 2010; Kurosaki et al. 2014). UPF1 is composed of three distinct domains: a cysteine- and histidine-rich $(\mathrm{CH})$ domain situated immediately downstream from an amino-terminal unstructured region, a helicase domain toward the middle, and a carboxy-terminal serine- and glutamine-rich (SO) domain (Fig. 2).

The $\mathrm{CH}$ domain folds into the helicase domain to inhibit the ATPase and RNA helicase activities (Kadlec et al. 2006; Chamieh et al. 2008; Fiorini et al. 2013). During NMD, an interaction between UPF1 and UPF2 displaces the $\mathrm{CH}$ domain, inducing a large conformational change in UPF1 that derepresses the inhibitory effect of the $\mathrm{CH}$ domain (Chamieh et al. 2008; Chakrabarti et al. 2011).

The helicase domain, which consists of two RecA-like domains, associates with ATP via the cleft situated between the two RecA-like domains (Chakrabarti et al. 2011; Fiorini et al. 2013). Recent data obtained using magnetic tweezers revealed that the helicase domain unwinds long double-stranded nucleic acids and translocates along single-stranded nucleic acids with high processivity (Fiorini et al. 2015). The tight grip of UPF1, which allows its high processivity, was recently proven to be essential for NMD (Kanaan et al. 2018).

Many [S/T]Q motifs in the amino-terminal unstructured region and the carboxy-terminal SQ domain of UPF1 become phosphorylated by the SMG1 kinase after TC recognition that triggers either 3'UTR EJC-dependent or 3'UTR EJC-independent NMD. As noted above, it is phosphorylated UPF1 that represses additional translation initiation events on the NMD target and recruits the downstream NMD factors (SMG5-SMG7 and/or PNRC2) for the sub-

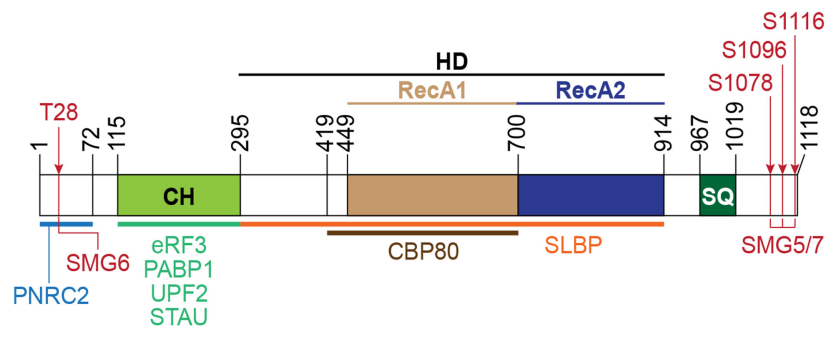

FIGURE 2. Schematic of UPF1 domains. The binding regions for UPF1-interacting proteins are indicated. Numbers and red arrows indicate amino acid positions and experimentally validated phosphorylation sites, respectively. $\mathrm{CH}$, cysteine- and histidine-rich domain; $\mathrm{HD}$, helicase domain; and SQ, serine- and glutamine-rich domain. strate decay steps of NMD. Down-regulation of SMG5, SMG6, SMG7, or PNRC2 causes phosphorylated UPF1 to accumulate, suggesting that inhibiting decay increases the amount of phosphorylated UPF1 (Durand et al. 2016). Extensive mutational analyses revealed that progressive phosphorylation of the various [S/T]Q motifs increases the ability of UPF1 to activate mRNA decay (Durand et al. 2016). While phosphorylation of any particular [S/T]Q motif does not seem to be crucial, a subset of motifs contributes to UPF1 function more significantly than do others (Yamashita et al. 2001; Ohnishi et al. 2003; Unterholzner and Izaurralde 2004; Fukuhara et al. 2005; Kashima et al. 2006). It is likely that phosphorylation at different residues results in a different binding preference for different downstream decay-inducing factors. For instance, UPF1 phosphorylation at residue T28 in the amino terminus or $\mathrm{S} 1096$ in the carboxyl terminus preferentially recruits SMG6 or SMG5-SMG7, respectively. Such phosphorylation site-dependent recruitments are known to be required for efficient NMD (Okada-Katsuhata et al. 2012). It remains to be determined if UPF1 phosphorylation at different residues occurs in a sequential or otherwise regulated manner. It is also unknown if the degree to which each of the possible downstream decay-inducing factors functions in NMD depends on what UPF1 residues have undergone phosphorylation. However, as additional evidence that UPF1 phosphorylation at different [S/T]Q motifs results in different outcomes, while UPF1 undergoes phosphorylation by both ATM and SMG1 kinases in cells exposed to ionizing radiation, down-regulating SMG1, unlike down-regulating ATM, inhibits NMD (Brumbaugh et al. 2004).

\section{UPF1 IN STAUFEN-MEDIATED mRNA DECAY (SMD)}

In NMD, UPF1 enrichment at a 3'UTR, whether the 3'UTR harbors an EJC or not, results in UPF1 joining to an upstream terminating ribosome. It is also possible that UPF1 recruitment to a terminating ribosome is mediated by an RNA-binding protein that simultaneously binds a 3'UTR and UPF1. This mode of recruitment typifies mRNA decay that is mediated by the double-stranded RNA-binding protein staufen (STAU)_-in mammals, either STAU1 or STAU2 - so as to trigger STAU-mediated mRNA decay (SMD) (Table 1; Fig. 3; Kim et al. 2005). Originally, STAU was identified as a cellular factor that functions to determine the spatiotemporal localization of maternal mRNAs in Drosophila oocytes and eggs (Broadus et al. 1998; Roegiers and Jan 2000; Park and Maquat 2013; Heraud-Farlow and Kiebler 2014). In mammals, STAUs are also involved in mRNA localization in, e.g., neurons and oocytes (Kiebler et al. 1999; Tang et al. 2001; Miki et al. 2005; Maquat and Gong 2009). Additionally, when STAU1 (Kim et al. 2005) or STAU2 (Park et al. 2013) binds to an mRNA 3'UTR, it can trigger translation-dependent 
TABLE 1. Features of UPF1-dependent RNA decay pathways

\begin{tabular}{lccccc}
\hline & & \multicolumn{3}{c}{ Required UPF1 activities } \\
\cline { 3 - 5 } Pathway & Translation dependency & ATPase & Helicase & Phosphorylation & Functional UPF1 kinase \\
\hline NMD & Yes & Yes & Yes & Yes & SMG1 \\
SMD & Yes & Yes & Yes & Yes & SMG1 \\
HMD & Yes & Yes & Yes & Yes & ATR, DNA-PK \\
GMD & No & Yes & Yes & Yes & ATM \\
RMD & Yes & $?$ & Yes & $?$ & ? \\
TumiD & $?$ & $?$ & Yes & No & - \\
\hline
\end{tabular}

and UPF1-dependent SMD. SMD, like NMD, targets diverse transcripts and participates in diverse cellular and physiological processes including myogenesis, adipogenesis, cell motility, and autophagy (Kim et al. 2005, 2007; Gong et al. 2009; Maquat and Gong 2009; Gong and Maquat 2011; Cho et al. 2012; Park and Maquat 2013; Paul et al. 2018).

In SMD, substrate selection is determined by STAU binding to a 3'UTR double-stranded structure, a so-called STAU-binding site (SBS), in target mRNAs (Kim et al. 2005, 2007). SBSs can be generated with an SMD target by either intramolecular base-pairing within the $3^{\prime} U T R$ or intermolecular base-pairing between a short interspersed nuclear element (SINE) within the 3'UTR and a partially complementary SINE within one or more computationally defined long noncoding RNAs, termed 1/2-sbsRNAs, and/ or one or more mRNAs (Kim et al. 2005, 2007; Gong and Maquat 2011; Gong et al. 2013; Lucas et al. 2018). If base-pairing occurs between two mRNAs via their $3^{\prime}$ UTR SINEs, e.g., Alu elements in humans, then both mRNAs are targeted by SMD; however, if base-pairing occurs between the 3'UTR SINE of an mRNA and a 1/2-sbsRNA that fails to undergo translation, only the mRNA is targeted for SMD (Bono et al. 2006; Gong and Maquat 2011; Gong et al. 2013).

SMD involves SBS-bound STAU directly recruiting UPF1 downstream from a TC, much as the EJC recruits UPF1 during NMD. However, since SMD does not involve an EJC, SMD is not restricted to newly synthesized mRNAs. While uncertain, it is likely that the mechanisms of SMD and NMD converge upon UPF1 activation by SMG1-mediated phosphorylation (Cho et al. 2013b). Therefore, it can be postulated that when an elongating ribosome reaches a TC, recruitment of UPF1 downstream from the TC-in the case of SMD, to the $3^{\prime} U T R$ via its direct interaction with STAU—links the termination event to mRNA decay. As is the case for NMD, where UPF2 displaces the $\mathrm{CH}$ domain of UPF1 and induces a conformational change in UPF1, STAU1 interacts with the $\mathrm{CH}$ domain of UPF1 (Gong et al. 2009) and does likewise, activating UPF1 ATP hydrolysis and helicase activity (Park et al. 2013) and triggering
UPF1 phosphorylation by SMG1 (Cho et al. 2013b). After that, phosphorylated UPF1 recruits PNRC2 that, as it does during NMD, elicits decapping followed by $5^{\prime}$-to- $3^{\prime}$ exoribonucleolytic cleavage of SMD-targeted mRNAs (Cho et al. 2009, 2012). It is currently unknown whether other decay-inducing factors, e.g., SMG5, SMG6, and SMG7 that engage in NMD are involved in SMD or whether the same or different [S/T]Q motifs in UPF1 are phosphorylated during SMD and NMD.

\section{UPF1 IN REPLICATION-DEPENDENT HISTONE mRNA DECAY (HMD)}

Mammalian cell proliferation requires a proper balance between the amounts of DNA and histone proteins. Balance is in part achieved by controlling the stabilities and translational efficiencies of replication-dependent histone mRNAs, which typically lack the poly $(A)$ tail found at the 3 '-ends of most eukaryotic mRNAs (Marzluff et al. 2008; Marzluff and Koreski 2017). Instead, of a poly(A) tail, these mRNAs harbor an evolutionarily conserved 3'UTR stemloop structure (Jaeger et al. 2005; Hoefig and Heissmeyer 2014) that is crucial for their rapid degradation at the end of the S phase of the cell cycle, i.e., after DNA has been duplicated, or under stressful conditions where DNA replication is inhibited (Sittman et al. 1983; Pandey and Marzluff 1987; Harris et al. 1991). Remarkably, the overall shape of this stem-loop structure is unique and specifically recognized by stem-loop-binding protein (SLBP; Tan et al. 2013). SLBP performs pivotal functions at multiple steps in the biogenesis of replication-dependent histone mRNAs, including pre-mRNA processing, mRNA export, translation, and degradation (Marzluff et al. 2008; Hoefig and Heissmeyer 2014; Marzluff and Koreski 2017).

SLBP-mediated replication-dependent histone mRNAs decay (HMD) is mechanistically reminiscent of NMD and SMD (Table 1; Fig. 3) in that HMD depends on translation and UPF1 recruitment downstream from the TC. Under normal conditions, CBC-dependent translation initiation factor (CTIF) preferentially associates with SLBP (Choe 

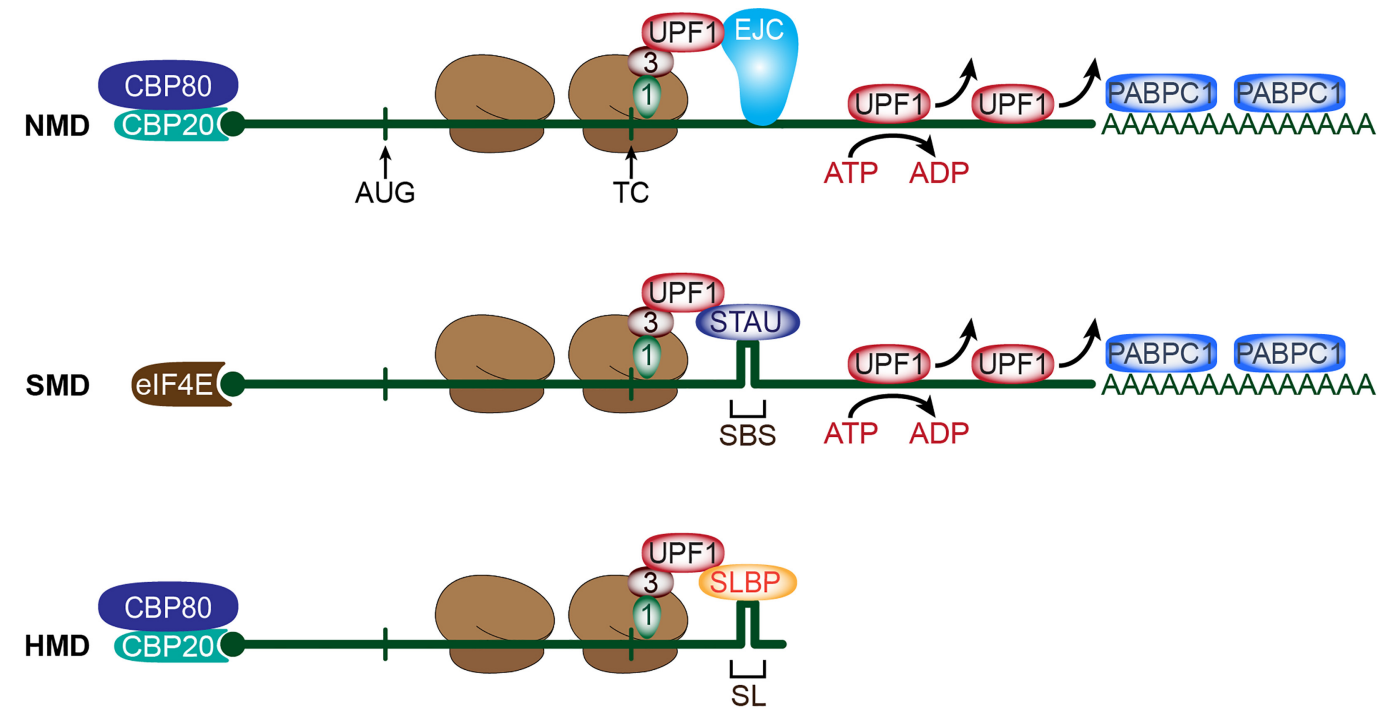

RMD

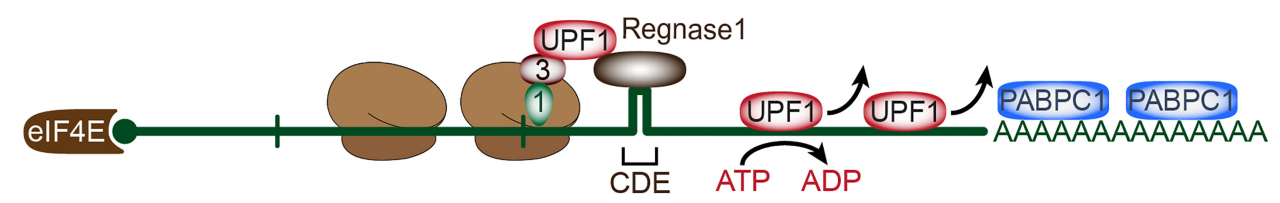

GMD
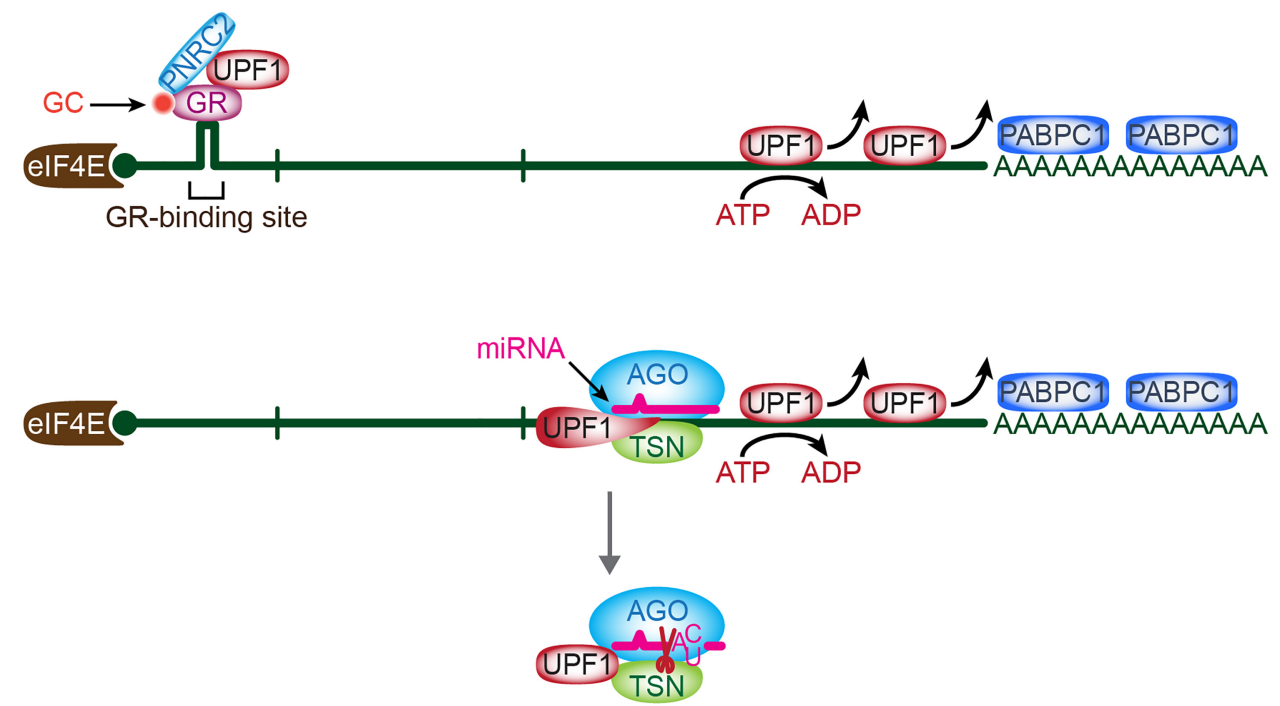

FIGURE 3. Various UPF1-dependent RNA decay pathways. Shown are six categories of RNA decay pathways that differ by how UPF1 engages with the substrate. UPF1 is engaged in NMD via either a $3^{\prime}$ UTR EJC or another $3^{\prime} U T R$ feature that attracts UPF1 and delays translation termination. UPF1 is engaged in SMD via 3'UTR-bound STAU1 or STAU2, and in HMD via a 3'UTR SLBP. GMD engages UPF1 via a GC-bound GR and RMD via regnase 1. Finally, TumiD engages UPF1 as a transiently or weakly associated constituent of the RNA-induced silencing complex, which consists of an AGO protein. Each of these pathways require the helicase activity of UPF1 and, of the mRNA decay pathways, all but GMD require the substrate be translated. The primary cap-binding protein(s) for each pathway are shown. SBS, STAU-binding site; SL, histone stem-loop; CDE, constitute decay element.

et al. 2013, 2014a), thus allowing for the increased stability and efficient translation of replication-dependent histone mRNAs (Choe et al. 2014a). Under stressful conditions that result in a DNA replication block, the phosphatidylinositol 3-kinase-related kinases ATR and DNA-PK are activated and phosphorylate UPF1 (Kaygun and Marzluff 2005; Choe et al. 2014a). Although it is unknown whether these kinases target free UPF1, SLBP-bound UPF1 or UPF1 in the SURF complex (Kaygun and Marzluff 2005), UPF1 phosphorylation, which is critical for HMD (Kaygun and Marzluff 2005), enhances UPF1 binding to SLBP and disrupts the interaction between SLBP and CTIF, thereby leading to the translational suppression of replication-dependent histone mRNAs (Choe et al. 2014a). Since HMD 
does not involve either UPF2 or STAU, possibly dissociation of the inhibitory interaction between the $\mathrm{CH}$ domain and helicase domain of UPF1 during HMD may be mediated by the amino-terminal half of SLBP, which interacts directly with the helicase domain of UPF1 and promotes UPF1 ATPase and helicase activities (Choe et al. 2014a). As another possibility, phosphorylation of the UPF1 [S/T] $\mathrm{Q}$ motifs by ATR or DNA-PK may be sufficient to trigger the large conformational change of UPF1 that is required to promote the helicase activity of UPF1, either by displacing the $\mathrm{CH}$ domain or by generating a platform favorable for SLBP binding.

The complex of SLBP and phosphorylated UPF1 preferentially recruits SMG5 and PNRC2, thereby triggering replication-dependent histone mRNA decapping followed by 5'-to-3' exoribonucleolytic decay (Choe et al. 2014a). In contrast to NMD, down-regulating either SMG6 or SMG7 does not significantly alter the efficiency of HMD (Choe et al. 2014a), suggesting that SLBP may influence which degradative activities are recruited. As an additional difference between HMD and NMD, decapping followed by $5^{\prime}$-to- $3^{\prime}$ exoribonucleolytic degradation during HMD is induced by an alternative pathway either simultaneously with or independently of PNRC2. Moreover, oligouridylation during HMD primarily by TUT7 and/or possibly TUT4 promotes 3 '-to-5' degradation, starting downstream from the stem-loop and continuing into the translated region, where ribosomes remain bound (Mullen and Marzluff 2008; Schmidt et al. 2011; Su et al. 2013; Lackey et al. 2016). As proposed for NMD, oligouridylated terminal sequences in histone mRNAs also provide a platform for loading the LSM1-7 complex, which activates decapping followed by XRN1-mediated 5'-to-3' degradation (Song and Kiledjian 2007; Rissland and Norbury 2009). It is quite likely that, like NMD and HMD, many if not all decay pathways that proceed from an mRNA 3 '-end involve oligouridylation to overcome higher-order RNA structural barriers to the $3^{\prime}$-to-5' exosome.

\section{UPF1 IN GLUCOCORTICOID RECEPTOR-MEDIATED mRNA DECAY (GMD)}

Glucocorticoid (GC) receptor (GR) is a DNA-binding transcription factor that belongs to the nuclear receptor superfamily and regulates various biological and physiological processes (Oakley and Cidlowski 2011; Santos et al. 2011; Vandevyver et al. 2012). Although it has long been appreciated that GR targets DNA, several studies have revealed that $G R$ also functions as an RNA-binding protein to elicit rapid degradation of target substrates (Dhawan et al. 2007, 2012; Kino et al. 2010; Ishmael et al. 2011; Cho et al. 2015; Park et al. 2015, 2016) in a process called GR-mediated mRNA decay (GMD) (Table 1; Fig. 3).

Recent biochemical and transcriptome-wide analyses point to a two-step model for GMD: mRNA recognition by $G R$ in the absence of a GC and, subsequently, rapid mRNA decay in the presence of a GC (Cho et al. 2015; Park et al. 2016). Unlike GR binding to DNAs, which occurs in response to a GC ligand, GR binding to RNAs occurs independent of a GC ligand. When cells are treated with a $G C$, the GR preexisting on target mRNAs associates with the GC, after which the GC-GR complex recruits PNRC2 (Cho et al. 2015; Park et al. 2016). The resulting complex is functionally inactive but relatively stable. It contains PNRC2 that appears to provide a binding platform for UPF1 and DCP1A because down-regulating PNRC2 abrogates the coimmunoprecipitation of UPF1 and DCP1A with GR (Cho et al. 2015; Park et al. 2016). Subsequent recruitment of Y-box-binding protein 1 (YBX1) and the endoribonuclease heat-responsive protein (HRSP)12 (also known as reactive intermediate imine deaminase $A$ homolog, or RIDA) activates the complex so as to elicit efficient GMD via PNRC2-mediated decapping followed by 5'-to-3' exoribonucleolytic cleavage (Park et al. 2016). As with other mRNA decay pathways, GMD may also involve 3'-to-5' exoribonucleolytic cleavage. Additionally, the known endoribonucleolytic activity of HRSP12 (Morishita et al. 1999; Mistiniene et al. 2003, 2005) may function in GMD.

Although GMD, NMD, SMD, and HMD involve UPF1 and PNRC2, GMD stands apart from the other pathways in several ways. First, unlike NMD, SMD, and HMD, GMD occurs independent of mRNA substrate translation: Blocking translation initiation using a strong hairpin structure in the 5'UTR does not alter GMD efficiency (Cho et al. 2015). Second, although NMD, SMD, and HMD involve communication between a terminating ribosome on a TC and cellular factors loaded onto the $3^{\prime}$ UTR of target mRNAs (the EJC or another $3^{\prime}$ UTR feature that results in UPF1 loading, STAU or SLBP, respectively), GMD does not require the GR-binding site to be in the $3^{\prime}$ UTR (Cho et al. 2015). Indeed, the first identified cellular GMD substrate, CCL2 mRNA, contains a GR-binding site in the 5'UTR (Cho et al. 2015). Third, GMD is a ligand-inducible mRNA decay pathway. GC treatment is sufficient for eliciting efficient GMD, as long as GMD substrates contain GR-occupied GR-binding sites (Cho et al. 2015; Park et al. 2015, 2016).

GMD manifests additional interesting features. GMD requires PNRC2, which interacts with the unstructured amino terminus of UPF1 (i.e., amino acids 1-72), the ATPase and helicase activities of UPF1 (Park et al. 2016), and UPF1 phosphorylation (Park et al. 2016). Whereas NMD preferentially utilizes SMG1-mediated UPF1 phosphorylation, GMD is not dependent on SMG1 (Cho et al. 2015) but instead preferentially uses ATM-mediated UPF1 phosphorylation (Park et al. 2016). As noted above, this suggests that SMG1 and ATM may phosphorylate UPF1 at different [S/T] $\mathrm{Q}$ motifs in the amino-terminal region and in the carboxyterminal SQ domain so as to generate binding platforms for different decay-inducing factors. 


\section{REGNASE 1-MEDIATED mRNA DECAY (RMD)}

Coordinated transcriptional and post-transcriptional regulation of gene expression in response to inflammation is crucial for immune homeostasis (Chovatiya and Medzhitov 2014). Many inflammatory mRNAs are very unstable because they contain a conserved $3^{\prime}$ UTR cis-acting element, such as an AU-rich element (ARE) or a constitutive decay element $(C D E)$, the latter of which forms a hairpin structure harboring a pyrimidine-purine-pyrimidine loop (Stoecklin et al. 2003; Glasmacher et al. 2010; Leppek et al. 2013). ARE-containing mRNAs are rapidly degraded in innate-immune cells in general, although they are stabilized upon activation of a set of pattern-recognition receptors, such as Toll-like receptors (Takeuchi and Akira 2010). The stability of ARE-containing mRNAs is determined by the ARE-mediated binding of trans-acting cellular factors that either stabilize or destabilize the mRNA. These factors include Hu antigen R (HuR; also known as embryonic lethal abnormal vision-like 1, ELAVL1), tristetraprolin (TTP), butyrate response factors 1 (BRF1) and BFR2, KH-type splicing regulatory protein (KSRP), and AU-rich element RNA-binding protein 1 (AUF1) (Gratacós and Brewer 2010; von Roretz et al. 2011; Schoenberg and Maquat 2012; Brooks and Blackshear 2013; Grammatikakis et al. 2017; Khabar 2017; Mayr 2017).

mRNAs harboring a CDE are selectively recognized and rapidly degraded by the ring finger- and $\mathrm{CCCH}$-type domain-containing protein known as roquin (Leppek et al. 2013). Recent studies revealed that $3^{\prime}$ UTR CDEs are also recognized by the zinc finger $\mathrm{CCCH}$-type containing 12 a protein known as regnase 1 (also known as ZC3H12A, and originally identified as monocyte chemotactic protein-induced protein 1; Mino et al. 2015; Takeuchi 2018). Regnase 1 contains a PilT amino-terminal (PIN)-like RNase domain (also called a NYN domain) that manifests endoribonuclease activity (Matsushita et al. 2009).

Although regnase 1 and roquin commonly recognize a $3^{\prime} U T R$, the molecular mechanisms underlying mRNA destabilization are quite different (Leppek et al. 2013; Mino et al. 2015). CDE-bound roquin initiates rapid mRNA degradation by recruiting a CCR4-NOT deadenylase complex, while regnase 1-mediated mRNA decay (RMD) proceeds in a UPF1- and a translation-dependent manner (Table 1; Fig. 3). Regnase 1 and roquin are in charge of tightly regulating inflammatory mRNA decay in acute and late phases of inflammation, respectively.

In terms of the mechanism, RMD, like NMD and SMD, depends on translation termination. In RMD, $3^{\prime}$ UTR-bound regnase 1 appears to be functionally equivalently to those $3^{\prime}$ UTR features that trigger NMD and SMD (see above). Taking cues from NMD, when an elongating ribosome reaches a TC during RMD, UPF1 may be recruited to the terminating ribosome either via the SURF complex or through promiscuous preassociation with the $3^{\prime} U T R$ of the target mRNA. UPF1 in the terminating ribosome may bridge the translation termination complex and downstream CDE-bound regnase 1 (Leppek et al. 2013; Mino et al. 2015). This could subsequently trigger regnase 1 endoribonuclease activity and can activate UPF1 helicase activity, which is critical for efficient RMD (Leppek et al. 2013). Whether RMD requires UPF1 phosphorylation and other decay-inducing factors recruited by UPF1 has yet to be tested.

\section{UPF1 IN TSN-MEDIATED microRNA DECAY (TumiD)}

MicroRNAs (miRNAs), which are short noncoding RNAs of $\sim 22 \mathrm{nt}$, mediate gene silencing by guiding a miRNA-induced silencing complex (miRISC) to miRNA-binding sites in the 3'UTR of target mRNAs (Duchaine and Fabian 2018; Gebert and MacRae 2019). A miRNA-loaded miRISC then triggers translation repression and possibly also degradation of target mRNAs. Although tremendous discoveries have expanded our understanding of miRNA biogenesis and function, research into miRNA decay is in its youth.

miRNA stability largely depends on the miRNA sequence itself and the extent of base-pairing to its various target mRNAs (Duchaine and Fabian 2018; Gebert and MacRae 2019). miRNA stability is also affected by environmental cues and differs among different cell types. A recent study showed that TSN, an endonuclease responsible for degrading A-to-I edited double-stranded RNAs (Nishikura 2016), also degrades a subset of miRNAs that harbor CA or UA dinucleotides in a process termed TSNmediated miRNA decay or TumiD (Table 1; Fig. 3; Elbarbary et al. 2017b). While UPF1 is not required in vitro to degrade TumiD targets that either are or are not associated with argonaute 2 (AGO2), which is a core component of miRISCs (Elbarbary et al. 2017b), UPF1 promotes TumiD in cells by dissociating miRNAs from their mRNA targets, rendering the miRNAs more susceptible to decay (Elbarbary et al. 2017a). TumiD requires UPF1 helicase activity but is not influenced by UPF1 phosphorylation (Elbarbary et al. 2017a). How UPF1 helicase activity is derepressed during TumiD is currently unknown.

\section{CONCLUSIONS}

It has long been recognized that UPF1 plays a central role in NMD. Moreover, as outlined in this review, accumulating evidence indicates that UPF1 contributes to various RNA decay pathways that include SMD, HMD, GMD, $\mathrm{RMD}$, and TumiD. It can be expected that changes in the cellular concentration of UPF1, which often occur during cellular development, differentiation and stress, will affect the various UPF1-dependent RNA decay pathways to different extents. It also should be noted that different cell types can manifest differences in the relative efficiencies of each UPF1-dependent pathway. For example, relative 
to HeLa cells, HEK293T cells manifest only a low degree of SMD, explaining how immunoprecipitation of HEK293Tcell transcripts using antibody to phosphorylated UPF1 readily identifies both $3^{\prime}$ UTR EJC-dependent and 3'UTR EJC-independent NMD targets but not SMD targets (Kurosaki et al. 2014). The finding that UPF1-dependent RNA decay pathways can influence one another also complicates their evaluation. For example, competition between STAU1 and UPF2 for binding to UPF1 results in competition between the SMD and NMD pathways (Gong et al. 2009). To complicate matters even further, UPF1 may be involved in previously uncharacterized RNA decay pathways. For instance, PNRC2 binding to nuclear receptors is not limited to the GR (Zhou et al. 2000, 2006; Zhou and Chen 2001), and several nuclear receptors can bind RNA (Lalli et al. 2000; Xu and Koenig 2004; Colley et al. 2008; Colley and Leedman 2011; Hentze et al. 2018). It follows that nuclear receptors in addition to GR may bind to specific RNAs, recruit PNRC2, and consequently elicit UPF1-dependent RNA decay. Moreover, there are undoubtedly other RNA-binding proteins that in the future will be discovered to recruit UPF1 to transcripts, some of which could trigger mRNA decay.

We conclude that UPF1 will be front and center to additional RNA decay pathways, providing cells with novel mechanisms to shape the cellular transcriptome in response to diverse biological or physiological environments.

\section{ACKNOWLEDGMENTS}

We thank Max Popp, Tatsuaki Kurosaki, Incheol Ryu, and Joori Park for comments on the manuscript, and Bill Marzluff for a helpful email. We apologize to colleagues whose work was not cited due to length limitations. This work was supported by the National Research Foundation of Korea (NRF) grants funded by the Korea government (MSIP; NRF-2015R1A3A2033665 and NRF-2018R1A5A1024261 to Y.K.K.), and a Korea University grant to Y.K.K. Work on NMD, SMD, TumiD, and other functions of UPF1 in the Maquat laboratory is funded by National Institutes of Health R01 GM059614 and R37 GM074593 to L.E.M.

\section{REFERENCES}

Anders KR, Grimson A, Anderson P. 2003. SMG-5, required for C. elegans nonsense-mediated mRNA decay, associates with SMG-2 and protein phosphatase 2A. EMBO J 22: 641-650. doi:10 .1093/emboj/cdg056

Apcher S, Daskalogianni C, Lejeune F, Manoury B, Imhoos G, Heslop L, Fahraeus R. 2011. Major source of antigenic peptides for the MHC class I pathway is produced during the pioneer round of mRNA translation. Proc Natl Acad Sci 108: 11572-11577. doi:10.1073/pnas.1104104108

Bhuvanagiri M, Schlitter AM, Hentze MW, Kulozik AE. 2010. NMD: RNA biology meets human genetic medicine. Biochem J 430: 365-377. doi:10.1042/BJ20100699

Boehm V, Gehring NH. 2016. Exon junction complexes: supervising the gene expression assembly line. Trends Genet 32: 724-735. doi:10.1016/j.tig.2016.09.003
Bokhari A, Jonchere V, Lagrange A, Bertrand R, Svrcek M, Marisa L, Buhard O, Greene M, Demidova A, Jia J, et al. 2018. Targeting nonsense-mediated mRNA decay in colorectal cancers with microsatellite instability. Oncogenesis 7: 70. doi:10.1038/s41389-0180079-x

Bono F, Ebert J, Lorentzen E, Conti E. 2006. The crystal structure of the exon junction complex reveals how it maintains a stable grip on mRNA. Cell 126: 713-725. doi:10.1016/j.cell.2006.08.006

Broadus J, Fuerstenberg S, Doe CQ. 1998. Staufen-dependent localization of prospero mRNA contributes to neuroblast daughter-cell fate. Nature 391: 792-795. doi:10.1038/35861

Brogna S, McLeod T, Petric M. 2016. The meaning of NMD: translate or perish. Trends Genet 32: 395-407. doi:10.1016/j.tig.2016.04 .007

Brooks SA, Blackshear PJ. 2013. Tristetraprolin (TTP): interactions with mRNA and proteins, and current thoughts on mechanisms of action. Biochim Biophys Acta 1829: 666-679. doi:10.1016/j .bbagrm.2013.02.003

Brumbaugh KM, Otterness DM, Geisen C, Oliveira V, Brognard J, Li X, Lejeune F, Tibbetts RS, Maquat LE, Abraham RT. 2004. The mRNA surveillance protein hSMG-1 functions in genotoxic stress response pathways in mammalian cells. Mol Cell 14: 585-598. doi:10.1016/j.molcel.2004.05.005

Bruno IG, Karam R, Huang L, Bhardwaj A, Lou CH, Shum EY, Song HW, Corbett MA, Gifford WD, Gecz J, et al. 2011. Identification of a microRNA that activates gene expression by repressing nonsense-mediated RNA decay. Mol Cell 42: 500-510. doi:10.1016/j.molcel.2011.04.018

Bühler M, Steiner S, Mohn F, Paillusson A, Mühlemann O. 2006. EJCindependent degradation of nonsense immunoglobulin- $\mu$ mRNA depends on 3' UTR length. Nat Struct Mol Biol 13: 462-464. doi:10.1038/nsmb1081

Celik A, He F, Jacobson A. 2017. NMD monitors translational fidelity 24/7. Curr Genet 63: 1007-1010. doi:10.1007/s00294-017-0709-4

Chakrabarti S, Jayachandran U, Bonneau F, Fiorini F, Basquin C, Domcke S, Le Hir H, Conti E. 2011. Molecular mechanisms for the RNA-dependent ATPase activity of Upf1 and its regulation by Upf2. Mol Cell 41: 693-703. doi:10.1016/j.molcel.2011.02.010

Chamieh H, Ballut L, Bonneau F, Le Hir H. 2008. NMD factors UPF2 and UPF3 bridge UPF1 to the exon junction complex and stimulate its RNA helicase activity. Nat Struct Mol Biol 15: 85-93. doi:10 $.1038 / \mathrm{nsmb} 1330$

Chan WK, Huang L, Gudikote JP, Chang YF, Imam JS, MacLean JA II, Wilkinson MF. 2007. An alternative branch of the nonsense-mediated decay pathway. EMBO J 26: 1820-1830. doi:10.1038/sj .emboj.7601628

Chen CY, Shyu AB. 2003. Rapid deadenylation triggered by a nonsense codon precedes decay of the RNA body in a mammalian cytoplasmic nonsense-mediated decay pathway. Mol Cell Biol 23: 4805-4813. doi:10.1128/MCB.23.14.4805-4813.2003

Chiu SY, Serin G, Ohara O, Maquat LE. 2003. Characterization of human Smg5/7a: a protein with similarities to Caenorhabditis elegans SMG5 and SMG7 that functions in the dephosphorylation of Upf1. RNA 9: 77-87. doi:10.1261/rna.2137903

Chiu SY, Lejeune F, Ranganathan AC, Maquat LE. 2004. The pioneer translation initiation complex is functionally distinct from but structurally overlaps with the steady-state translation initiation complex. Genes Dev 18: 745-754. doi:10.1101/gad.1170204

Cho H, Kim KM, Kim YK. 2009. Human proline-rich nuclear receptor coregulatory protein 2 mediates an interaction between mRNA surveillance machinery and decapping complex. Mol Cell 33: 75-86. doi:10.1016/j.molcel.2008.11.022

Cho H, Kim KM, Han S, Choe J, Park SG, Choi SS, Kim YK. 2012. Staufen1-mediated mRNA decay functions in adipogenesis. Mol Cell 46: 495-506. doi:10.1016/j.molcel.2012.03.009 
Cho H, Han S, Choe J, Park SG, Choi SS, Kim YK. 2013a. SMG5PNRC2 is functionally dominant compared with SMG5-SMG7 in mammalian nonsense-mediated mRNA decay. Nucleic Acids Res 41: 1319-1328. doi:10.1093/nar/gks1222

Cho H, Han S, Park OH, Kim YK. 2013b. SMG1 regulates adipogenesis via targeting of staufen 1-mediated mRNA decay. Biochim Biophys Acta 1829: 1276-1287. doi:10.1016/j.bbagrm.2013.10.004

Cho H, Park OH, Park J, Ryu I, Kim J, Ko J, Kim YK. 2015. Glucocorticoid receptor interacts with PNRC2 in a ligand-dependent manner to recruit UPF1 for rapid mRNA degradation. Proc Natl Acad Sci 112: E1540-E1549. doi:10.1073/pnas.1409612112

Choe J, Oh N, Park S, Lee YK, Song OK, Locker N, Chi SG, Kim YK. 2012. Translation initiation on mRNAs bound by nuclear cap-binding protein complex CBP80/20 requires interaction between CBP80/20-dependent translation initiation factor and eukaryotic translation initiation factor 3g. J Biol Chem 287: 18500-18509. doi:10.1074/jbc.M111.327528

Choe J, Kim KM, Park S, Lee YK, Song OK, Kim MK, Lee BG, Song HK, Kim YK. 2013. Rapid degradation of replication-dependent histone mRNAs largely occurs on mRNAs bound by nuclear cap-binding proteins 80 and 20. Nucleic Acids Res 41: 1307-1318. doi:10 $.1093 /$ nar/gks1196

Choe J, Ahn SH, Kim YK. 2014a. The mRNP remodeling mediated by UPF1 promotes rapid degradation of replication-dependent histone mRNA. Nucleic Acids Res 42: 9334-9349. doi:10.1093/nar/ gku610

Choe J, Ryu I, Park OH, Park J, Cho H, Yoo JS, Chi SW, Kim MK, Song HK, Kim YK. 2014b. elF4Alll enhances translation of nuclear cap-binding complex-bound mRNAs by promoting disruption of secondary structures in 5'UTR. Proc Natl Acad Sci 111: E45774586. doi:10.1073/pnas.1409695111

Chovatiya R, Medzhitov R. 2014. Stress, inflammation, and defense of homeostasis. Mol Cell 54: 281-288. doi:10.1016/j.molcel.2014.03 .030

Colley SM, Leedman PJ. 2011. Steroid receptor RNA aactivator-a nuclear receptor coregulator with multiple partners: insights and challenges. Biochimie 93: 1966-1972. doi:10.1016/j.biochi.2011 .07 .004

Colley SM, lyer KR, Leedman PJ. 2008. The RNA coregulator SRA, its binding proteins and nuclear receptor signaling activity. IUBMB Life 60: 159-164. doi:10.1002/iub.22

Couttet P, Grange T. 2004. Premature termination codons enhance mRNA decapping in human cells. Nucleic Acids Res 32: 488494. doi:10.1093/nar/gkh218

Dever TE, Green R. 2012. The elongation, termination, and recycling phases of translation in eukaryotes. Cold Spring Harb Perspect Biol 4: a013706. doi:10.1101/cshperspect.a013706

Dhawan L, Liu B, Blaxall BC, Taubman MB. 2007. A novel role for the glucocorticoid receptor in the regulation of monocyte chemoattractant protein-1 mRNA stability. J Biol Chem 282: 1014610152. doi:10.1074/jbc.M605925200

Dhawan L, Liu B, Pytlak A, Kulshrestha S, Blaxall BC, Taubman MB. 2012. Y-box binding protein 1 and RNase UK114 mediate monocyte chemoattractant protein 1 mRNA stability in vascular smooth muscle cells. Mol Cell Biol 32: 3768-3775. doi:10.1128/MCB $.00846-12$

Duchaine TF, Fabian MR. 2018. Mechanistic insights into microRNAmediated gene silencing. Cold Spring Harb Perspect Biol doi:10 $.1101 /$ cshperspect.a032771.

Durand S, Lykke-Andersen J. 2013. Nonsense-mediated mRNA decay occurs during elF4F-dependent translation in human cells. Nat Struct Mol Biol 20: 702-709. doi:10.1038/nsmb.2575

Durand S, Franks TM, Lykke-Andersen J. 2016. Hyperphosphorylation amplifies UPF1 activity to resolve stalls in nonsense-mediated mRNA decay. Nat Commun 7: 12434. doi:10.1038/ncomms12434
Eberle AB, Stalder L, Mathys H, Orozco RZ, Mühlemann O. 2008. Posttranscriptional gene regulation by spatial rearrangement of the $3^{\prime}$ untranslated region. PLoS Biol 6: e92. doi:10.1371/journal .pbio.0060092

Eberle AB, Lykke-Andersen S, Mühlemann O, Jensen TH. 2009. SMG6 promotes endonucleolytic cleavage of nonsense mRNA in human cells. Nat Struct Mol Biol 16: 49-55. doi:10.1038/nsmb .1530

El-Bchiri J, Guilloux A, Dartigues P, Loire E, Mercier D, Buhard O, Sobhani I, de la Grange P, Auboeuf D, Praz F, et al. 2008. Nonsense-mediated mRNA decay impacts MSI-driven carcinogenesis and anti-tumor immunity in colorectal cancers. PLoS One 3: e2583. doi:10.1371/journal.pone.0002583

Elbarbary RA, Miyoshi K, Hedaya O, Myers JR, Maquat LE. 2017a. UPF1 helicase promotes TSN-mediated miRNA decay. Genes Dev 31: 1483-1493. doi:10.1101/gad.303537.117

Elbarbary RA, Miyoshi K, Myers JR, Du P, Ashton JM, Tian B, Maquat LE. 2017b. Tudor-SN-mediated endonucleolytic decay of human cell microRNAs promotes G1/S phase transition. Science 356: 859-862. doi:10.1126/science.aai9372

Feng Q, Jagannathan S, Bradley RK. 2017. The RNA surveillance factor UPF1 represses myogenesis via its E3 ubiquitin ligase activity. Mol Cell 67: 239-251 e236. doi:10.1016/j.molcel.2017 .05 .034

Fiorini F, Boudvillain M, Le Hir H. 2013. Tight intramolecular regulation of the human Upf1 helicase by its $\mathrm{N}$ - and $\mathrm{C}$-terminal domains. Nucleic Acids Res 41: 2404-2415. doi:10.1093/nar/gks1320

Fiorini F, Bagchi D, Le Hir H, Croquette V. 2015. Human Upf1 is a highly processive RNA helicase and translocase with RNP remodelling activities. Nat Commun 6: 7581. doi:10.1038/ncomms8581

Franks TM, Singh G, Lykke-Andersen J. 2010. Upf1 ATPase-dependent mRNP disassembly is required for completion of nonsensemediated mRNA decay. Cell 143: 938-950. doi:10.1016/j.cell .2010.11.043

Fukuhara N, Ebert J, Unterholzner L, Lindner D, Izaurralde E, Conti E. 2005. SMG7 is a 14-3-3-like adaptor in the nonsense-mediated mRNA decay pathway. Mol Cell 17: 537-547. doi:10.1016/j molcel.2005.01.010

Ge Z, Quek BL, Beemon KL, Hogg JR. 2016. Polypyrimidine tract binding protein 1 protects mRNAs from recognition by the nonsense-mediated mRNA decay pathway. elife 5: e11155. doi:10 .7554/eLife. 11155

Gebert LFR, MacRae IJ. 2019. Regulation of microRNA function in animals. Nat Rev Mol Cell Biol 20: 21-37. doi:10.1038/s41580-0180045-7.

Gehring NH, Kunz JB, Neu-Yilik G, Breit S, Viegas MH, Hentze MW, Kulozik AE. 2005. Exon-junction complex components specify distinct routes of nonsense-mediated mRNA decay with differential cofactor requirements. Mol Cell 20: 65-75. doi:10.1016/j.molcel 2005.08.012

Glasmacher E, Hoefig KP, Vogel KU, Rath N, Du L, Wolf C, Kremmer E, Wang $X$, Heissmeyer V. 2010. Roquin binds inducible costimulator mRNA and effectors of mRNA decay to induce microRNA-independent post-transcriptional repression. Nat Immunol 11: 725733. doi:10.1038/ni.1902

Gonatopoulos-Pournatzis T, Cowling VH. 2014. Cap-binding complex (CBC). Biochem J 457: 231-242. doi:10.1042/BJ20131214

Gong C, Maquat LE. 2011. IncRNAs transactivate STAU1-mediated mRNA decay by duplexing with 3' UTRs via Alu elements. Nature 470: 284-288. doi:10.1038/nature09701

Gong C, Kim YK, Woeller CF, Tang Y, Maquat LE. 2009. SMD and NMD are competitive pathways that contribute to myogenesis: effects on PAX3 and myogenin mRNAs. Genes Dev 23: 54-66. doi:10.1101/gad.1717309 
Gong C, Tang Y, Maquat LE. 2013. mRNA-mRNA duplexes that autoelicit Staufen1-mediated mRNA decay. Nat Struct Mol Biol 20: 1214-1220. doi:10.1038/nsmb.2664

Grammatikakis I, Abdelmohsen K, Gorospe M. 2017. Posttranslational control of HuR function. Wiley Interdiscip Rev RNA 8: e1372. doi: 10.1002/wrna.1372.

Gratacós FM, Brewer G. 2010. The role of AUF1 in regulated mRNA decay. Wiley Interdiscip Rev RNA 1: 457-473. doi:10.1002/wrna .26

Harris ME, Böhni R, Schneiderman MH, Ramamurthy L, Schümperli D, Marzluff WF. 1991. Regulation of histone mRNA in the unperturbed cell cycle: evidence suggesting control at two posttranscriptional steps. Mol Cell Biol 11: 2416-2424. doi:10.1128/ MCB.11.5.2416

He F, Jacobson A. 2015. Nonsense-mediated mRNA decay: degradation of defective transcripts is only part of the story. Annu Rev Genet 49: 339-366. doi:10.1146/annurev-genet-112414-054639

Hellen CUT. 2018. Translation termination and ribosome recycling in eukaryotes. Cold Spring Harb Perspect Biol 10. doi: 10.1101/ cshperspect.a032656.

Hentze MW, Castello A, Schwarzl T, Preiss T. 2018. A brave new world of RNA-binding proteins. Nat Rev Mol Cell Biol 19: 327-341. doi:10.1038/nrm.2017.130

Heraud-Farlow JE, Kiebler MA. 2014. The multifunctional Staufen proteins: conserved roles from neurogenesis to synaptic plasticity. Trends Neurosci 37: 470-479. doi:10.1016/j.tins.2014.05.009

Hoefig KP, Heissmeyer V. 2014. Degradation of oligouridylated histone mRNAs: see UUUUU and goodbye. Wiley Interdiscip Rev RNA 5: 577-589. doi:10.1002/wrna.1232

Hogg JR, Goff SP. 2010. Upf1 senses 3'UTR length to potentiate mRNA decay. Cell 143: 379-389. doi:10.1016/j.cell.2010.10.005

Hoshino S, Imai M, Kobayashi T, Uchida N, Katada T. 1999. The eukaryotic polypeptide chain releasing factor (eRF3/GSPT) carrying the translation termination signal to the $3^{\prime}-\operatorname{poly}(\mathrm{A})$ tail of mRNA. Direct association of erf3/GSPT with polyadenylate-binding protein. J Biol Chem 274: 16677-16680. doi:10.1074/jbc.274.24 .16677

Huang L, Wilkinson MF. 2012. Regulation of nonsense-mediated mRNA decay. Wiley Interdiscip Rev RNA 3: 807-828. doi:10 .1002/wrna.1137

Hug N, Cáceres JF. 2014. The RNA helicase DHX34 activates NMD by promoting a transition from the surveillance to the decay-inducing complex. Cell Rep 8: 1845-1856. doi:10.1016/j.celrep.2014.08 .020

Hug N, Longman D, Cáceres JF. 2016. Mechanism and regulation of the nonsense-mediated decay pathway. Nucleic Acids Res 44: 1483-1495. doi:10.1093/nar/gkw010

Huntzinger E, Kashima I, Fauser M, Sauliere J, Izaurralde E. 2008. SMG6 is the catalytic endonuclease that cleaves mRNAs containing nonsense codons in metazoan. RNA 14: 2609-2617. doi:10 $.1261 /$ rna.1386208

Hurt JA, Robertson AD, Burge CB. 2013. Global analyses of UPF1 binding and function reveal expanded scope of nonsense-mediated mRNA decay. Genome Res 23: 1636-1650. doi:10.1101/gr .157354 .113

Imamachi N, Salam KA, Suzuki Y, Akimitsu N. 2017. A GC-rich sequence feature in the $3^{\prime}$ UTR directs UPF1-dependent mRNA decay in mammalian cells. Genome Res 27: 407-418. doi:10.1101/gr .206060 .116

Ishigaki Y, Li X, Serin G, Maquat LE. 2001. Evidence for a pioneer round of mRNA translation: $m R N A$ s subject to nonsense-mediated decay in mammalian cells are bound by CBP80 and CBP20. Cell 106: 607-617. doi:10.1016/S0092-8674(01)00475-5

Ishmael FT, Fang X, Houser KR, Pearce K, Abdelmohsen K, Zhan M, Gorospe M, Stellato C. 2011. The human glucocorticoid receptor as an RNA-binding protein: global analysis of glucocorticoid receptor-associated transcripts and identification of a target RNA motif. J Immunol 186: 1189-1198. doi:10.4049/jimmunol .1001794

Isken O, Maquat LE. 2007. Quality control of eukaryotic mRNA: safeguarding cells from abnormal mRNA function. Genes Dev 21: 1833-1856. doi:10.1101/gad.1566807

Isken O, Kim YK, Hosoda N, Mayeur GL, Hershey JW, Maquat LE. 2008. Upf1 phosphorylation triggers translational repression during nonsense-mediated mRNA decay. Cell 133: 314-327. doi:10 .1016/j.cell.2008.02.030

Ivanov PV, Gehring NH, Kunz JB, Hentze MW, Kulozik AE. 2008 Interactions between UPF1, eRFs, PABP and the exon junction complex suggest an integrated model for mammalian NMD pathways. EMBO J 27: 736-747. doi:10.1038/emboj.2008.17

Ivanov A, Mikhailova T, Eliseev B, Yeramala L, Sokolova E, Susorov D, Shuvalov A, Schaffitzel C, Alkalaeva E. 2016. PABP enhances release factor recruitment and stop codon recognition during translation termination. Nucleic Acids Res 44: 7766-7776. doi:10.1093/ nar/gkw635

Jaeger S, Barends S, Giegé R, Eriani G, Martin F. 2005. Expression of metazoan replication-dependent histone genes. Biochimie 87: 827-834. doi:10.1016/j.biochi.2005.03.012

Jia J, Furlan A, Gonzalez-Hilarion S, Leroy C, Gruenert DC, Tulasne D, Lejeune F. 2015. Caspases shutdown nonsense-mediated mRNA decay during apoptosis. Cell Death Differ 22: 1754-1763. doi:10 .1038/cdd.2015.18

Joazeiro CAP. 2017. Ribosomal stalling during translation: providing substrates for ribosome-associated protein quality control. Annu Rev Cell Dev Biol 33: 343-368. doi:10.1146/annurev-cellbio111315-125249

Kadlec J, Izaurralde E, Cusack S. 2004. The structural basis for the interaction between nonsense-mediated mRNA decay factors UPF2 and UPF3. Nat Struct Mol Biol 11:330-337. doi:10.1038/nsmb741

Kadlec J, Guilligay D, Ravelli RB, Cusack S. 2006. Crystal structure of the UPF2-interacting domain of nonsense-mediated mRNA decay factor UPF1. RNA 12: 1817-1824. doi:10.1261/rna.177606

Kanaan J, Raj S, Decourty L, Saveanu C, Croquette V, Le Hir H. 2018. UPF1-like helicase grip on nucleic acids dictates processivity. Nat Commun 9: 3752. doi:10.1038/s41467-018-06313-y

Karousis ED, Mühlemann O. 2018. Nonsense-mediated mRNA decay begins where translation ends. Cold Spring Harb Perspect Biol doi 10.1101/cshperspect.a032862.

Karousis ED, Nasif S, Mühlemann O. 2016. Nonsense-mediated mRNA decay: novel mechanistic insights and biological impact. Wiley Interdiscip Rev RNA 7: 661-682. doi:10.1002/wrna.1357

Kashima I, Yamashita A, Izumi N, Kataoka N, Morishita R, Hoshino S, Ohno M, Dreyfuss G, Ohno S. 2006. Binding of a novel SMG-1Upf1-eRF1-eRF3 complex (SURF) to the exon junction complex triggers Upf1 phosphorylation and nonsense-mediated mRNA decay. Genes Dev 20: 355-367. doi:10.1101/gad.1389006

Kaygun H, Marzluff WF. 2005. Regulated degradation of replicationdependent histone mRNAs requires both ATR and Upf1. Nat Struct Mol Biol 12: 794-800. doi:10.1038/nsmb972

Khabar KS. 2017. Hallmarks of cancer and AU-rich elements. Wiley Interdiscip Rev RNA 8: e1368. doi: 10.1002/wrna.1368.

Khoshnevis S, Gross T, Rotte C, Baierlein C, Ficner R, Krebber H. 2010. The iron-sulphur protein RNase $L$ inhibitor functions in translation termination. EMBO Rep 11: 214-219. doi:10.1038/embor.2009 .272

Kiebler MA, Hemraj I, Verkade P, Köhrmann M, Fortes P, Marión RM, Ortín J, Dotti CG. 1999. The mammalian staufen protein localizes to the somatodendritic domain of cultured hippocampal neurons: implications for its involvement in mRNA transport. J Neurosci 19: 288-297. doi:10.1523/JNEUROSCI.19-01-00288.1999 
Kim YK, Furic L, Desgroseillers L, Maquat LE. 2005. Mammalian Staufen1 recruits Upf1 to specific mRNA 3'UTRs so as to elicit mRNA decay. Cell 120: 195-208. doi:10.1016/j.cell.2004.11.050

Kim YK, Furic L, Parisien M, Major F, DesGroseillers L, Maquat LE. 2007. Staufen 1 regulates diverse classes of mammalian transcripts. EMBO J 26: 2670-2681. doi:10.1038/sj.emboj.7601712

Kim KM, Cho H, Choi K, Kim J, Kim BW, Ko YG, Jang SK, Kim YK. 2009. A new MIF4G domain-containing protein, CTIF, directs nuclear cap-binding protein CBP80/20-dependent translation. Genes Dev 23: 2033-2045. doi:10.1101/gad.1823409

Kino T, Hurt DE, Ichijo T, Nader N, Chrousos GP. 2010. Noncoding RNA gas 5 is a growth arrest- and starvation-associated repressor of the glucocorticoid receptor. Sci Signal 3: ra8.

Kishor A, Ge Z, Hogg JR. 2018. hnRNP L-dependent protection of normal mRNAs from NMD subverts quality control in B cell lymphoma. EMBO J 38: e99128. doi: 10.15252/embj.201899128.

Kurosaki T, Maquat LE. 2013. Rules that govern UPF1 binding to mRNA 3' UTRs. Proc Natl Acad Sci 110: 3357-3362. doi:10 $.1073 /$ pnas. 1219908110

Kurosaki T, Li W, Hoque M, Popp MW, Ermolenko DN, Tian B, Maquat LE. 2014. A post-translational regulatory switch on UPF1 controls targeted mRNA degradation. Genes Dev 28: 19001916. doi:10.1101/gad.245506.114

Kurosaki T, Miyoshi K, Myers JR, Maquat LE. 2018. NMD-degradome sequencing reveals ribosome-bound intermediates with 3 '-end non-templated nucleotides. Nat Struct Mol Biol 25: 940-950. doi:10.1038/s41594-018-0132-7

Kurosaki T, Popp MW, Maquat LE. 2019. Nonsense-mediated mRNA decay: quality and quantity control of gene expression in health and disease. Nat Rev Mol Cell Biol (in press).

Lackey PE, Welch JD, Marzluff WF. 2016. TUT7 catalyzes the uridylation of the $3^{\prime}$ end for rapid degradation of histone mRNA. RNA 22: 1673-1688. doi:10.1261/rna.058107.116

Lai T, Cho H, Liu Z, Bowler MW, Piao S, Parker R, Kim YK, Song H. 2012. Structural basis of the PNRC2-mediated link between mRNA surveillance and decapping. Structure 20: 2025-2037. doi:10.1016/j.str.2012.09.009

Lalli E, Ohe K, Hindelang C, Sassone-Corsi P. 2000. Orphan receptor DAX-1 is a shuttling RNA binding protein associated with polyribosomes via mRNA. Mol Cell Biol 20: 4910-4921. doi:10.1128/MCB 20.13.4910-4921.2000

Le Hir H, Izaurralde E, Maquat LE, Moore MJ. 2000. The spliceosome deposits multiple proteins 20-24 nucleotides upstream of mRNA exon-exon junctions. EMBO J 19: 6860-6869. doi:10.1093/ emboj/19.24.6860

Le Hir H, Saulière J, Wang Z. 2016. The exon junction complex as a node of post-transcriptional networks. Nat Rev Mol Cell Biol 17: 41-54. doi:10.1038/nrm.2015.7

Lejeune F, Ishigaki Y, Li X, Maquat LE. 2002. The exon junction complex is detected on CBP80-bound but not elF4E-bound mRNA in mammalian cells: dynamics of mRNP remodeling. EMBO $\mathrm{J}$ 21: 3536-3545. doi:10.1093/emboj/cdf345

Lejeune F, Li X, Maquat LE. 2003. Nonsense-mediated mRNA decay in mammalian cells involves decapping, deadenylating, and exonucleolytic activities. Mol Cell 12: 675-687. doi:10.1016/S10972765(03)00349-6

Leppek K, Schott J, Reitter S, Poetz F, Hammond MC, Stoecklin G. 2013. Roquin promotes constitutive mRNA decay via a conserved class of stem-loop recognition motifs. Cell 153: 869-881. doi:10 .1016/j.cell.2013.04.016

Liu C, Karam R, Zhou Y, Su F, Ji Y, Li G, Xu G, Lu L, Wang C, Song M, et al. 2014. The UPF1 RNA surveillance gene is commonly mutated in pancreatic adenosquamous carcinoma. Nat Med 20: 596-598. doi:10.1038/nm.3548
Loh B, Jonas S, Izaurralde E. 2013. The SMG5-SMG7 heterodimer directly recruits the CCR4-NOT deadenylase complex to mRNAs containing nonsense codons via interaction with POP2. Genes Dev 27: 2125-2138. doi:10.1101/gad.226951.113

Lou CH, Shao A, Shum EY, Espinoza JL, Huang L, Karam R, Wilkinson MF. 2014. Posttranscriptional control of the stem cell and neurogenic programs by the nonsense-mediated RNA decay pathway. Cell Rep 6: 748-764. doi:10.1016/j.celrep.2014.01 .028

Lucas BA, Lavi E, Shiue L, Cho H, Katzman S, Miyoshi K, Siomi MC, Carmel L, Ares M Jr, Maquat LE. 2018. Evidence for convergent evolution of SINE-directed Staufen-mediated mRNA decay. Proc Natl Acad Sci 115: 968-973. doi:10.1073/pnas.1715531115

Maquat LE, Gong C. 2009. Gene expression networks: competing mRNA decay pathways in mammalian cells. Biochem Soc Trans 37: 1287-1292. doi:10.1042/BST0371287

Maquat LE, Serin G. 2001. Nonsense-mediated mRNA decay: insights into mechanism from the cellular abundance of human Upf1, Upf2, Upf3, and Upf3X proteins. Cold Spring Harb Symp Quant Biol 66: 313-320. doi:10.1101/sqb.2001.66.313

Maquat LE, Tarn WY, Isken O. 2010. The pioneer round of translation: features and functions. Cell 142: 368-374. doi:10.1016/j.cell.2010 .07 .022

Marzluff WF, Koreski KP. 2017. Birth and death of histone mRNAs. Trends Genet 33: 745-759. doi:10.1016/j.tig.2017.07.014

Marzluff WF, Wagner EJ, Duronio RJ. 2008. Metabolism and regulation of canonical histone mRNAs: life without a poly(A) tail. Nat Rev Genet 9: 843-854. doi:10.1038/nrg2438

Matsuda D, Hosoda N, Kim YK, Maquat LE. 2007. Failsafe nonsensemediated mRNA decay does not detectably target elF4E-bound mRNA. Nat Struct Mol Biol 14: 974-979. doi:10.1038/nsmb1297

Matsushita K, Takeuchi O, Standley DM, Kumagai Y, Kawagoe T, Miyake T, Satoh T, Kato H, Tsujimura T, Nakamura H, et al. 2009. Zc3h12a is an RNase essential for controlling immune responses by regulating mRNA decay. Nature 458: 1185-1190. doi:10 .1038/nature07924

Mayr C. 2017. Regulation by 3'-untranslated regions. Annu Rev Genet 51: 171-194. doi:10.1146/annurev-genet-120116-024704

Melero R, Hug N, López-Perrote A, Yamashita A, Cáceres JF, Llorca O. 2016. The RNA helicase DHX34 functions as a scaffold for SMG1mediated UPF1 phosphorylation. Nat Commun 7: 10585. doi:10 .1038/ncomms10585

Miki T, Takano K, Yoneda Y. 2005. The role of mammalian Staufen on mRNA traffic: a view from its nucleocytoplasmic shuttling function. Cell Struct Funct 30: 51-56. doi:10.1247/csf.30.51

Mino T, Murakawa Y, Fukao A, Vandenbon A, Wessels HH, Ori D, Uehata T, Tartey S, Akira S, Suzuki Y, et al. 2015. Regnase-1 and roquin regulate a common element in inflammatory mRNAs by spatiotemporally distinct mechanisms. Cell 161: 1058-1073. doi:10.1016/j.cell.2015.04.029

Mistiniene E, Luksa V, Sereikaite J, Naktinis V. 2003. Oligomeric assembly and ligand binding of the members of protein family YER057c/YIL051c/YJGF. Bioconjug Chem 14: 1243-1252. doi:10.1021/bc0341066

Mistiniene E, Pozdniakovaite N, Popendikyte V, Naktinis V. 2005. Structure-based ligand binding sites of protein p14.5, a member of protein family YER057c/YIL051c/YjgF. Int J Biol Macromol 37: 61-68. doi:10.1016/j.ijbiomac.2005.08.008

Morishita R, Kawagoshi A, Sawasaki T, Madin K, Ogasawara T, Oka T, Endo Y. 1999. Ribonuclease activity of rat liver perchloric acidsoluble protein, a potent inhibitor of protein synthesis. J Biol Chem 274: 20688-20692. doi:10.1074/jbc.274.29.20688

Mugridge JS, Ziemniak M, Jemielity J, Gross JD. 2016. Structural basis of mRNA-cap recognition by Dcp1-Dcp2. Nat Struct Mol Biol 23: 987-994. doi:10.1038/nsmb.3301 
Mullen TE, MarzluffWF. 2008. Degradation of histone mRNA requires oligouridylation followed by decapping and simultaneous degradation of the mRNA both $5^{\prime}$ to $3^{\prime}$ and $3^{\prime}$ to $5^{\prime}$. Genes Dev 22: 50-65. doi:10.1101/gad.1622708

Müller-McNicoll M, Neugebauer KM. 2014. Good cap/bad cap: how the cap-binding complex determines RNA fate. Nat Struct Mol Biol 21: 9-12. doi:10.1038/nsmb.2751

Neu-Yilik G, Raimondeau E, Eliseev B, Yeramala L, Amthor B, Deniaud A, Huard K, Kerschgens K, Hentze MW, Schaffitzel C, et al. 2017. Dual function of UPF3B in early and late translation termination. EMBO J 36: 2968-2986. doi:10.15252/embj .201797079

Nguyen LS, Wilkinson MF, Gecz J. 2014. Nonsense-mediated mRNA decay: inter-individual variability and human disease. Neurosci Biobehav Rev 46: 175-186. doi:10.1016/j.neubiorev .2013.10.016

Nicholson P, Gkratsou A, Josi C, Colombo M, Mühlemann O. 2018. Dissecting the functions of SMG5, SMG7, and PNRC2 in nonsense-mediated mRNA decay of human cells. RNA 24: 557-573. doi:10.1261/rna.063719.117

Nishikura K. 2016. A-to-l editing of coding and non-coding RNAs by ADARs. Nat Rev Mol Cell Biol 17: 83-96. doi:10.1038/nrm.2015.4

Nojima T, Rebelo K, Gomes T, Grosso AR, Proudfoot NJ, CarmoFonseca M. 2018. RNA polymerase II phosphorylated on CTD serine 5 interacts with the spliceosome during co-transcriptional splicing. Mol Cell 72: 369-379 e364. doi:10.1016/j.molcel.2018.09 .004

Oakley RH, Cidlowski JA. 2011. Cellular processing of the glucocorticoid receptor gene and protein: new mechanisms for generating tissue-specific actions of glucocorticoids. J Biol Chem 286: 3177-3184.

Ohnishi T, Yamashita A, Kashima I, Schell T, Anders KR, Grimson A, Hachiya T, Hentze MW, Anderson P, Ohno S. 2003. Phosphorylation of hUPF1 induces formation of mRNA surveillance complexes containing hSMG-5 and hSMG-7. Mol Cell 12: 1187-1200. doi:10 .1016/S1097-2765(03)00443-X

Okada-Katsuhata Y, Yamashita A, Kutsuzawa K, Izumi N, Hirahara F, Ohno S. 2012. N- and C-terminal Upf1 phosphorylations create binding platforms for SMG-6 and SMG-5:SMG-7 during NMD. Nucleic Acids Res 40: 1251-1266. doi:10.1093/nar/gkr791

Pandey NB, Marzluff WF. 1987. The stem-loop structure at the $3^{\prime}$ end of histone mRNA is necessary and sufficient for regulation of histone mRNA stability. Mol Cell Biol 7: 4557-4559. doi:10.1128/ MCB.7.12.4557

Park E, Maquat LE. 2013. Staufen-mediated mRNA decay. Wiley Interdiscip Rev RNA 4: 423-435. doi:10.1002/wrna.1168

Park E, Gleghorn ML, Maquat LE. 2013. Staufen2 functions in Staufen1-mediated mRNA decay by binding to itself and its paralog and promoting UPF1 helicase but not ATPase activity. Proc Natl Acad Sci 110: 405-412. doi:10.1073/pnas.1213508110

Park OH, Do E, Kim YK. 2015. A new function of glucocorticoid receptor: regulation of mRNA stability. BMB Rep 48: 367-368. doi:10 .5483/BMBRep.2015.48.7.131

Park OH, Park J, Yu M, An HT, Ko J, Kim YK. 2016. Identification and molecular characterization of cellular factors required for glucocorticoid receptor-mediated mRNA decay. Genes Dev 30: 20932105. doi:10.1101/gad.286484.116

Paul S, Dansithong W, Figueroa KP, Scoles DR, Pulst SM. 2018. Staufen 1 links RNA stress granules and autophagy in a model of neurodegeneration. Nat Commun 9: 3648. doi:10.1038/s41467018-06041-3

Pisarev AV, Skabkin MA, Pisareva VP, Skabkina OV, Rakotondrafara AM, Hentze MW, Hellen CU, Pestova TV. 2010. The role of $A B C E 1$ in eukaryotic posttermination ribosomal recycling. Mol Cell 37: 196-210. doi:10.1016/j.molcel.2009.12.034
Popp MW, Maquat LE. 2015. Attenuation of nonsense-mediated mRNA decay facilitates the response to chemotherapeutics. Nat Commun 6: 6632. doi:10.1038/ncomms7632

Raimondeau E, Bufton JC, Schaffitzel C. 2018. New insights into the interplay between the translation machinery and nonsense-mediated mRNA decay factors. Biochem Soc Trans 46: 503-512. doi:10.1042/BST20170427

Rissland OS, Norbury CJ. 2009. Decapping is preceded by 3' uridylation in a novel pathway of bulk mRNA turnover. Nat Struct Mol Biol 16: 616-623. doi:10.1038/nsmb.1601

Roegiers F, Jan YN. 2000. Staufen: a common component of mRNA transport in oocytes and neurons? Trends Cell Biol 10: 220-224. doi:10.1016/S0962-8924(00)01767-0

Rufener SC, Mühlemann O. 2013. elF4E-bound mRNPs are substrates for nonsense-mediated mRNA decay in mammalian cells. Nat Struct Mol Biol 20: 710-717. doi:10.1038/nsmb.2576

Santos GM, Fairall L, Schwabe JW. 2011. Negative regulation by nuclear receptors: a plethora of mechanisms. Trends Endocrinol Metab 22: 87-93.

Sato H, Maquat LE. 2009. Remodeling of the pioneer translation initiation complex involves translation and the karyopherin importin $\beta$. Genes Dev 23: 2537-2550. doi:10.1101/gad.1817109

Saveanu C, Jacquier A. 2016. How cells kill a "killer" messenger. eLife 5: e16076. doi: 10.7554/eLife.16076.

Schmidt MJ, West S, Norbury CJ. 2011. The human cytoplasmic RNA terminal U-transferase ZCCHC11 targets histone mRNAs for degradation. RNA 17: 39-44. doi:10.1261/rna.2252511

Schoenberg DR, Maquat LE. 2012. Regulation of cytoplasmic mRNA decay. Nat Rev Genet 13: 246-259. doi:10.1038/nrg3160

Schuller AP, Green R. 2018. Roadblocks and resolutions in eukaryotic translation. Nat Rev Mol Cell Biol 19: 526-541. doi:10.1038/ s41580-018-0011-4

Serin G, Gersappe A, Black JD, Aronoff R, Maquat LE. 2001. Identification and characterization of human orthologues to Saccharomyces cerevisiae Upf2 protein and Upf3 protein (Caenorhabditis elegans SMG-4). Mol Cell Biol 21: 209-223. doi:10.1128/MCB.21.1.209-223.2001

Sharma A, Yilmaz A, Marsh K, Cochrane A, Boris-Lawrie K. 2012. Thriving under stress: selective translation of HIV-1 structural protein mRNA during Vpr-mediated impairment of elF4E translation activity. PLoS Pathog 8: e1002612. doi:10.1371/journal.ppat .1002612

Singh G, Rebbapragada I, Lykke-Andersen J. 2008. A competition between stimulators and antagonists of Upf complex recruitment governs human nonsense-mediated mRNA decay. PLoS Biol 6: e111. doi:10.1371/journal.pbio.0060111

Singh G, Kucukural A, Cenik C, Leszyk JD, Shaffer SA, Weng Z, Moore MJ. 2012. The cellular EJC interactome reveals higher-order mRNP structure and an EJC-SR protein nexus. Cell 151: 750-764. doi:10.1016/j.cell.2012.10.007

Singh G, Pratt G, Yeo GW, Moore MJ. 2015. The clothes make the mRNA: past and present trends in mRNP fashion. Annu Rev Biochem 84: 325-354. doi:10.1146/annurev-biochem-080111092106

Sittman DB, Graves RA, Marzluff WF. 1983. Histone mRNA concentrations are regulated at the level of transcription and mRNA degradation. Proc Natl Acad Sci 80: 1849-1853. doi:10.1073/pnas.80.7 .1849

Song MG, Kiledjian M. 2007. 3' Terminal oligo U-tract-mediated stimulation of decapping. RNA 13: 2356-2365. doi:10.1261/rna .765807

Stoecklin G, Lu M, Rattenbacher B, Moroni C. 2003. A constitutive decay element promotes tumor necrosis factor $\alpha$ mRNA degradation via an AU-rich element-independent pathway. Mol Cell Biol 23: 3506-3515. doi:10.1128/MCB.23.10.3506-3515.2003 
Su W, Slepenkov SV, Slevin MK, Lyons SM, Ziemniak M, Kowalska J, Darzynkiewicz E, Jemielity J, Marzluff WF, Rhoads RE. 2013. mRNAs containing the histone $3^{\prime}$ stem-loop are degraded primarily by decapping mediated by oligouridylation of the $3^{\prime}$ end. RNA 19: 1-16. doi:10.1261/rna.034470.112

Takahashi S, Araki Y, Ohya Y, Sakuno T, Hoshino S, Kontani K, Nishina H, Katada T. 2008. Upf1 potentially serves as a RING-related E3 ubiquitin ligase via its association with Upf3 in yeast. RNA 14: 1950-1958. doi:10.1261/rna.536308

Takeuchi O. 2018. Endonuclease Regnase-1/Monocyte chemotactic protein-1-induced protein-1 (MCPIP1) in controlling immune responses and beyond. Wiley Interdiscip Rev RNA 9: e1449. doi: 10.1002/wrna.1449.

Takeuchi O, Akira S. 2010. Pattern recognition receptors and inflammation. Cell 140: 805-820. doi:10.1016/j.cell.2010.01.022

Tan D, Marzluff WF, Dominski Z, Tong L. 2013. Structure of histone mRNA stem-loop, human stem-loop binding protein, and 3 'hExo ternary complex. Science 339: 318-321. doi:10.1126/science .1228705

Tang SJ, Meulemans D, Vazquez L, Colaco N, Schuman E. 2001. A role for a rathomolog of staufen in the transport of RNA to neuronal dendrites. Neuron 32: 463-475. doi:10.1016/S0896-6273(01)00493-7

Trcek T, Sato H, Singer RH, Maquat LE. 2013. Temporal and spatial characterization of nonsense-mediated mRNA decay. Genes Dev 27: 541-551. doi:10.1101/gad.209635.112

Uchida N, Hoshino S, Imataka H, Sonenberg N, Katada T. 2002. A novel role of the mammalian GSPT/eRF3 associating with poly(A)binding protein in cap/poly(A)-dependent translation. J Biol Chem 277: 50286-50292. doi:10.1074/jbc.M203029200

Unterholzner L, Izaurralde E. 2004. SMG7 acts as a molecular link between mRNA surveillance and mRNA decay. Mol Cell 16: 587 596. doi:10.1016/j.molcel.2004.10.013

Vandevyver S, Dejager L, Libert C. 2012. On the trail of the glucocorticoid receptor: into the nucleus and back. Traffic 13: 364-374.

von Roretz C, Di Marco S, Mazroui R, Gallouzi IE. 2011. Turnover of AU-rich-containing mRNAs during stress: a matter of survival. Wiley Interdiscip Rev RNA 2: 336-347. doi:10.1002/wrna.55
Wang J, Gudikote JP, Olivas OR, Wilkinson MF. 2002. Boundary-independent polar nonsense-mediated decay. EMBO Rep 3: 274-279. doi:10.1093/embo-reports/kvf036

Weng Y, Czaplinski K, Peltz SW. 1996. Identification and characterization of mutations in the UPF1 gene that affect nonsense suppression and the formation of the Upf protein complex but not mRNA turnover. Mol Cell Biol 16: 5491-5506. doi:10.1128/MCB.16.10 .5491

Woodward LA, Mabin JW, Gangras P, Singh G. 2017. The exon junction complex: a lifelong guardian of mRNA fate. Wiley Interdiscip Rev RNA 8: e1411. doi:10.1002/wrna.1411.

Xu B, Koenig RJ. 2004. An RNA-binding domain in the thyroid hormone receptor enhances transcriptional activation. $\mathrm{J} \mathrm{Biol} \mathrm{Chem}$ 279: 33051-33056. doi:10.1074/jbc.M404930200

Yamashita A, Ohnishi T, Kashima I, Taya Y, Ohno S. 2001. Human SMG-1, a novel phosphatidylinositol 3-kinase-related protein kinase, associates with components of the mRNA surveillance complex and is involved in the regulation of nonsense-mediated mRNA decay. Genes Dev 15: 2215-2228. doi:10.1101/gad .913001

Zhou DJ, Chen SA. 2001. PNRC2 is a $16 \mathrm{kDa}$ coactivator that interacts with nuclear receptors through an $\mathrm{SH} 3$-binding motif. Nucleic Acids Res 29: 3939-3948. doi:10.1093/nar/29.19.3939

Zhou D, Quach KM, Yang C, Lee SY, Pohajdak B, Chen S. 2000. PNRC: a proline-rich nuclear receptor coregulatory protein that modulates transcriptional activation of multiple nuclear receptors including orphan receptors SF1 (steroidogenic factor 1) and ERR 1 (estrogen related receptor $\alpha-1$ ). Mol Endocrinol 14: 986-998. doi:10.1210/mend.14.7.0480

Zhou D, Ye JJ, Li Y, Lui K, Chen S. 2006. The molecular basis of the interaction between the proline-rich SH3-binding motif of PNRC and estrogen receptor $\alpha$. Nucleic Acids Res 34: 5974-5986. doi:10.1093/nar/gkl764

Zünd D, Gruber AR, Zavolan M, Mühlemann O. 2013. Translation-dependent displacement of UPF1 from coding sequences causes its enrichment in 3' UTRs. Nat Struct Mol Biol 20: 936-943. doi:10 .1038/nsmb.2635 